\title{
Daidzein Augments Cholesterol Homeostasis via ApoE to Promote Functional Recovery in Chronic Stroke
}

\author{
Eunhee Kim, ${ }^{1,2}$ Moon-Sook Woo, ${ }^{1}$ Luye Qin, ${ }^{1}$ Thong Ma, ${ }^{1}$ Cesar D. Beltran, ${ }^{1}$ Yi Bao, ${ }^{1}$ Jason A. Bailey, ${ }^{3}$ Dale Corbett, ${ }^{4}$ \\ ㅈajiv R. Ratan, ${ }^{1,2}$ Debomoy K. Lahiri, ${ }^{3}$ and Sunghee Cho ${ }^{1,2}$ \\ ${ }^{1}$ Burke-Cornell Medical Research Institute, White Plains, New York 10605, ${ }^{2}$ Feil Family Brain and Mind Research Institute, Weill Cornell Medical College, \\ New York, New York 10021, ${ }^{3}$ Institute of Psychiatric Research, Department of Psychiatry, Neuroscience Research Center, Indiana University School of \\ Medicine, Indianapolis, Indiana 46202, and ${ }^{4} \mathrm{Heart}$ and Stroke Foundation Canadian Partnership for Stroke Recovery, University of Ottawa and University \\ of Toronto, Ottawa, Ontario K1G 5Z3, Canada
}

Stroke is the world's leading cause of physiological disability, but there are currently no available agents that can be delivered early after stroke to enhance recovery. Daidzein, a soy isoflavone, is a clinically approved agent that has a neuroprotective effect in vitro, and it promotes axon growth in an animal model of optic nerve crush. The current study investigates the efficacy of daidzein on neuroprotection and functional recovery in a clinically relevant mouse model of stroke recovery. In light of the fact that cholesterols are essential lipid substrates in injury-induced synaptic remodeling, we found that daidzein enhanced the cholesterol homeostasis genetic program, including $L x r$ and downstream transporters, Apoe, Abcal, and Abcgl genes in vitro. Daidzein also elevated the cholesterol homeostasis genes in the poststroke brain with Apoe, the highest expressing transporter, but did not affect infarct volume or hemispheric swelling. Despite the absence of neuroprotection, daidzein improved motor/gait function in chronic stroke and elevated synaptophysin expression. However, the daidzein-enhanced functional benefits and synaptophysin expression were abolished in Apoe-knock-out mice, suggesting the importance of daidzein-induced ApoE upregulation in fostering stroke recovery. Dissociation between daidzein-induced functional benefits and the absence of neuroprotection further suggest the presence of nonoverlapping mechanisms underlying recovery processes versus acute pathology. With its known safety in humans, early and chronic use of daidzein aimed at augmenting ApoE may serve as a novel, translatable strategy to promote functional recovery in stroke patients without adverse acute effect.

Key words: ApoE; cholesterol transporter; daidzein; motor/gait function; stroke recovery

Significance Statement

There have been recurring translational failures in treatment strategies for stroke. One underlying issue is the disparity in outcome analysis between animal and clinical studies. The former mainly depends on acute infarct size, whereas long-term functional recovery is an important outcome in patients. In an attempt to identify agents that promote functional recovery, we discovered that an FDA-approved soy isoflavone, daidzein, improved stroke-induced behavioral deficits via enhancing cholesterol homeostasis in chronic stroke, and this occurs without causing adverse effects in the acute phase. With its known safety in humans, the study suggests that the early and chronic use of daidzein serves as a potential strategy to promote functional recovery in stroke patients.

\section{Introduction}

Improvements in acute stroke patient care have resulted in reduced stroke mortality, leaving more survivors with severe

\footnotetext{
Received July 31, 2015; revised Sept. 11, 2015; accepted 0ct. 12, 2015.

Author contributions:S.C. designed research; E.K.,M.-S.W., L.Q., T.M., C.D.B., Y.B., and J.A.B. performed research;

E.K., M.-S.W., L.Q., T.M., Y.B., J.A.B., D.C., R.R.R., D.K.L., and S.C. analyzed data; S.C. wrote the paper.

This work was supported by National Institutes of Health Grants HL82511 and HL82511-04S1, Winifred Masterson Burke Foundation Grant NS077897 to S.C., Alzheimer's Association Grants AG18379 and AG18884 to D.K.L., and the Miriam and Sheldon G. Adelson Foundation to R.R.R. We thank Renée Haskew-Layton for primary astrocyte cultures and Yuan-Wen Ge for generating APOE promoter construct.

The authors declare no competing financial interests.
}

disability and a long road of recovery. Despite demands in developing potential strategies to aid functional recovery in stroke, there is a paucity of medical treatments available to treat poststroke impairment and promote recovery. Studies showed that stroke initiates metabolic and genetic changes that persist for weeks to months following the initial insult (Carmichael, 2006;

Correspondence should be addressed to Dr. Sunghee Cho, Feil Family Brain and Mind Research Institute, Weill Cornell Medical College at Burke Medical Research Institute, 785 Mamaroneck Avenue, White Plains, NY 10605 E-mail: suc2002@med.cornell.edu.

DOI:10.1523/JNEUROSCI.2890-15.2015

Copyright $\odot 2015$ the authors $\quad 0270-6474 / 15 / 3515113-14 \$ 15.00 / 0$ 
Nudo, 2007). However, understanding of the mechanism underlying the repair/restorative processes and identification of biological targets in chronic stroke is largely limited.

Consumption of soy is associated with numerous health benefits against obesity, cancer, osteoporosis, cardiovascular disease, and immune deficiency (Orgaard and Jensen, 2008; Wenzel et al., 2008). Daidzein, an isoflavone, is a major component of soy with structural similarity to estrogen. It exerts an anti-inflammatory effect, lowers lipid levels, and increases mitochondrial biogenesis (Ricketts et al., 2005; Rasbach and Schnellmann, 2008; Wang et al., 2008). As an activator of nuclear receptor peroxisome proliferator-activated receptors (PPARs), daidzein enhances transcription of PPARsdependent genes, including liver $\mathrm{X}$ receptors (LXRs, Nrlh gene family in mice). By heterodimerizing with retinoid X receptors (RXRs), LXRs regulate the transcription of cholesterol transporter genes, Apoe, Abcal, and Abcg1 (Whitney et al., 2002), either directly or through sterol-independent regulatory element and enhancer sites (Shih et al., 2000; Kennedy et al., 2001; Langmann et al., 2002).

The cholesterol transporters provide lipid substrates for maintenance of membrane and synaptic integrity in normal and injury-induced synaptic remodeling. Reduced availability of lipid substrates is associated with neurodegenerative conditions, whereas administration of endogenous steroids that enhance the processes improves outcomes (Chen et al., 2011). ApoE is the most abundant cholesterol transporter in the CNS and plays a vital role in cholesterol homeostasis, neuronal repair, synaptic plasticity, and $\beta$-amyloid peptide (A $\beta$ ) clearance (Mahley and Rall, 2000; Cramer et al., 2012). Although expressed less in the CNS, Abcal promotes cholesterol efflux by preferentially lipidating naive ApoE, whereas Abcg1 acts on partially lipidated ApoE (Karten et al., 2006; W.S. Kim, et al., 2008). Notably, daidzein upregulates the expression of Abcg1 (Mezei et al., 2003; Gao et al., 2008), and it promotes axonal outgrowth in cultured hippocampal neurons via estrogen receptor signaling (Wang et al., 2008). Previously, we reported that daidzein overcame the inhibition of axonal outgrowth induced by myelin-associated glycoproteins in vitro and promoted regeneration of axons in an optic nerve crush model in vivo (Ma et al., 2010). Furthermore, studies by others reported that daidzein exerted neuroprotection in oxygenglucose deprived conditions (Hurtado et al., 2012) and enhanced recovery in rats following stroke (Hurtado et al., 2012; Stout et al., 2013). Because daidzein is a fairly safe agent that has been widely consumed as a soy component, we investigated whether daidzein is a potential neuroprotective and recovery agent in stroke and underlying events that are associated with these benefits. Here we report that daidzein, without affecting infarct size, promoted functional recovery via enhancing the cholesterol homeostasis program with Apoe being a critical component.

\section{Materials and Methods}

Study design. Experiments were performed with in vitro culture systems and in vivo using mice. For in vitro studies, three independent experiments were performed with duplicated samples at a given drug concentration. For in vivo studies, the use of animals and procedures was approved by the Institutional Animal Care and Use Committee of Weill Medical College of Cornell University and in accordance with the Institutional Animal Care and Use Committee, National Institutes of Health, and ARRIVE guidelines. The number of animals was calculated a priori by power calculation. Eleven animals per group were targeted to reach power 0.83 at a significance level of $<0.05$ assuming $25 \%$ difference in mean, a $20 \%$ SD at the $95 \%$ confidence level. Mice were randomized to receive sham or middle cerebral artery occlusion (MCAO) surgery. In certain cases, surgeons could not be blinded to the identity of groups at the time of surgery due to higher body weight or phenotype associated with Apoe knock-out (KO) mice. Mice were randomly selected by drawing different colored balls to receive vehicle or daidzein. The identity of the drug was concealed (coded A or B) by a third party and administered to animals blinded to experimenters. Because of the chronic nature of the study, each animal received a tattoo and their identity and treatment were blinded to the persons who assessed injury size and performed the behavior tests.

Cell cultures. HT22 murine hippocampal cells were cultured in DMEM with $4500 \mathrm{mg} / \mathrm{dl}$ glucose (Sigma-Aldrich), L-glutamine, and pyridoxine hydrochloride. C8-D1A immortalized mouse astrocyte cells (CRL-2541, American Type Culture Collection) were cultured in the DMEM. These cultures were supplemented with 10\% FBS (Mediatech), 100 IU penicillin and $100 \mu \mathrm{g} / \mathrm{ml}$ streptomycin (Invitrogen) at $37^{\circ} \mathrm{C}$ in a humidified $5 \%$ $\mathrm{CO}_{2}$ incubator.

Primary neuron-enriched cultures were generated from the papain digestion of cortical tissue harvested from E14.5 embryos of C57 mice. The resulting cells were plated at a density of $1.04 \times 10^{5}$ cells $/ \mathrm{cm}^{2}$ in 6-well plates in Neurobasal media supplemented with 2\% B27, $0.5 \mathrm{~mm}$ glutamine, and penicillin/streptomycin. After $1 \mathrm{~d}$ in culture, the cells were maintained in media containing $10 \mu \mathrm{M} 5$ '-fluoro- 2 '-deoxyuridine to kill off non-neuronal cells. The cells were treated after 7 DIV with media lacking mitotic inhibitors and consisted of $>99 \%$ neurons as assessed by MAP2 and GFAP immunocytochemistry (data not shown).

For astrocyte cultures, cortical tissue was harvested from postnatal day 1 mice, digested with papain, and plated at $1.5 \times 10^{3} \mathrm{cells} / \mathrm{cm}^{2}$ in 6 -well plates in MEM (Mediatech) supplemented with 10\% horse serum and penicillin/ streptomycin. After the astrocytes reached confluency ( $\sim 2$ weeks), the cultures were treated with $8 \mu \mathrm{M}$ cytosine-D-arabinofuranoside for $3 \mathrm{~d}$ to kill off contaminating nonastrocyte cells (Haskew-Layton et al., 2010).

Daidzein and T0901317 treatment in vitro culture. Neurons and astrocytes at 7 and 14 DIV, respectively, were treated with daidzein (Sigma-Aldrich) and T0901317 (Tocris Bioscience). The indicated concentrations of daidzein and T0901317 were added in the culture media with the absence of mitotic inhibitors. Twenty-four hours later, mRNA was harvested using TRI Reagent (Molecular Research Center) and purified using the Direct-zol RNA MiniPrep kit (Zymo Research) with in-column DNaseI digestion.

ApoE promoter activity assay. U373 human glioblastoma cells were maintained in MEM, supplemented with 10\% FBS (Atlanta Biologicals) and an antibiotic-antimytotic mixture (Mediatech). The day before transfection, cells were transferred to 96-well plates at a density of 50,000 cells per well. Cells were transfected with either the pGL3-Basic vector (Promega) or the pGL3 vector containing $1.1 \mathrm{~kb}$ of the $5^{\prime}$ upstream regulatory promoter region of the human $A p o E$ gene controlling expression of the firefly luciferase reporter gene ( $h A P O E 1.1)$. Cells were simultaneously transfected with 285 ng of the pGL3-based plasmid (vector or hAPOE1.1) and $15 \mathrm{ng}$ of the pRLSV40 plasmid (Promega) expressing renilla luciferase under the constitutive SV40 promoter as an internal control. Plasmid DNA was transfected into the cells using $0.75 \mu \mathrm{l}$ per well of the Transfectin transfection reagent (Bio-Rad) in serum- and antibiotic-free medium. Two hours after transfection, cells were treated with vehicle or the indicated concentrations of daidzein in MEM containing 10\% FBS and antibiotics for $48 \mathrm{~h}$ with $n=6$ per treatment. Cells were then lysed, and both firefly and renilla luciferase activities were measured using the Dual Luciferase kit (Promega), per the manufacturer's instructions. Results are expressed as the ratio of firefly/renilla luciferase activity. Toxicity was evaluated by a lactate dehydrogenase enzyme activity assay kit, per the manufacturer's instructions (Sigma-Aldrich).

Animals. Experiments were performed in 10- to 11-week-old male C57 (C57 bl/6) and Apoe KO (C57 background) mice purchased from The Jackson Laboratory. The mice were housed at the institute's animal facility, which maintained temperature, humidity, and $12 \mathrm{~h}$ light/dark cycle. A maximum of 5 mice was housed in a cage with an individual ventilating system and irradiated bedding (1/8" Bed O's Cobs, Anderson). Sterilized food (PicoLab Rodent diet 5053, LabDiet) and water were freely accessible in their cage.

Acute and stroke recovery models and daidzein treatment. Transient MCAO was performed in mice according to previously described methods (E. Kim et al., 2012; Qin et al., 2014). Mice were anesthetized with isoflurane (5\% induction and $1.5 \%-2.0 \%$ maintenance) with a mixture 
of oxygen and nitrogen (30\%/70\%). A 6-0 Teflon-coated black monofilament surgical suture (Doccol) was inserted into the exposed external carotid artery, advanced into the internal carotid artery, and wedged into the circle of Willis to obstruct the origin of the MCA and transiently occlude for $30 \mathrm{~min}$. Cerebral blood flow was continuously monitored 15 min before stroke, during $30 \mathrm{~min}$ MCAO and 15 min of reperfusion by Laser-Doppler flowmetry (Periflux System 5010; Perimed). Mice were then placed in a recovery cage until the animal regained consciousness and resumed activity. Using a rectal probe controlled by Masterflex water pump on an operating table and thermistor temperature controller (Cole-Parmer), animal's body temperatures were maintained at $37 \pm$ $0.5^{\circ} \mathrm{C}$ during entire surgical procedures and recovery after the surgery. The mice were then returned to their home cages where they were previously housed together. Buprenorphine, lidocaine, and buprivacaine were administered during postischemia as analgesics. Inclusion and exclusion criteria for mice were based on the severity of ischemia. Animals exhibiting reduced cerebral blood flow $>80 \%$ during $\mathrm{MCAO}$ and restored cerebral blood flow $>80 \%$ by $10 \mathrm{~min}$ following reperfusion were included in the study.

Our proximal MCAO by an intraluminar thread method produced an infarct $\sim 40 \mathrm{~mm}^{3}$ ( $\sim 30 \%$ of a hemisphere) and mostly confined to the striatum with incidental damage in somatosensory cortex. The size of the basal ganglia in the rodent brain as a proportion of total brain volume is approximately twofold higher than that in the human brain (Swanson, 1995). Therefore, subcortical infarcts produced by these methods would be approximately twofold larger than those in humans when anatomical proportions between the species are considered. As subcortical stroke in human ranges from $4.5 \%$ to $14 \%$ of a hemisphere (Carmichael, 2005), the current mouse stroke model generates proportionally similar magnitude of subcortical injury as human subcortical stroke.

For long-term stroke recovery, mice received moxifloxacin $(100 \mathrm{mg} /$ $\mathrm{kg}$ ) for $3 \mathrm{~d}$. The prophylactic antibiotic treatment was shown to effectively reduce mortality in an animal model of stroke by attenuating peripheral infection (Meisel et al., 2004). In addition, saline was subcutaneously administered daily, and hydrogel $\left(\right.$ Clear $\left.\mathrm{H}_{2} \mathrm{O}\right)$ was given to prevent dehydration. With the implementation of poststroke care (antibiotic regimen, rehydration, and feeding hydrogels with soft diet) during the acute period ( $<1$ week), mice start to regain their body weight by day 5 and continue to recover from stroke. Animals were randomly selected for vehicle or daidzein treatment. Vehicle or daidzein $(10 \mathrm{mg} / \mathrm{kg}$, SigmaAldrich) was administered subcutaneously within 30 min of reperfusion after confirming the reperfusion of blood flow, daily for $7 \mathrm{~d}$ and then every other day up to 1 month.

Tissue preparation. Brains were excised, frozen, and sectioned using an unbiased stereological sampling strategy to reflect the MCA territory in both hemispheres as previously described (E. Kim et al., 2014). Tissue sections with $30 \mu \mathrm{m}$ thicknesses were collected serially at $600 \mu \mathrm{m}$ intervals for analysis of infarct volume and immunohistochemistry. Sections in between were cut in half and collected for each hemisphere to determine mRNA and protein levels.

Measurement of infarct volume and hemispheric swelling. Serial sections representing the entire MCA territory were subjected to a phase-contrast microscope to visualize infarcted area. Infarct volume was determined using Axiovision software (Carl Zeiss). For edema assessment during acute phase, percentage hemispheric swelling (\%HS) is calculated from the difference in volume between two hemispheres and then divided by contralateral hemisphere volume according to a formula: $\% \mathrm{HS}=$ [(ipsilateral volume - contralateral volume)/contralateral volume] $\times$ 100 (Lin et al., 1993). At 4 weeks after ischemia, noninjured, scar, and contralateral tissue volumes were measured, and infarct volume was estimated by subtracting the remaining ipsilateral volume from contralateral volume.

Real time RT-PCR. Relative mRNA levels were quantified with realtime RT-PCR using fluorescent TaqMan technology as described previously (E. Kim et al., 2012, 2014). Total RNA from brain tissues or cell line cultures was reverse transcribed using QuantiTech reverse transcription kit (QIAGEN), according to the manufacturer's protocol. PCR primers and probes specific for the genes in this study were obtained as TaqMan predeveloped assay reagents for gene expres- sion (Invitrogen). Primers used were Ppary (Mm00440945_m1); Lxr (Nr1h) (Mm00443451_m1); Scarb1 (Mm00450236_m1); Ldlr (Mm0 0440169_m1); Abcg1 (Mm00437390_m1); Abca1 (Mm01350760_m1); Apoe (Mm00437573_m1); Lrp1 (Mm00464608_m1); Synaptophysin (Mm00436850_m1); Gap43 (Mm00500404_m1); Psd95 (Mm00492 193_m1);Gfap (Mm00546086_m1);Arginase-I (Mm00475988_m1); Fas (Mm00662319_m1); Lpl (Mm00434764_m1); Srebp1 (Mm00550 338_m1); $\beta$-actin (Mm00607939_s1). $\beta$-Actin was used as an internal control for normalization of samples. The PCR was performed using FastStart Universal Probe Master Mix (Roche) in an Applied Biosystems 7500 Fast Real-Time PCR system (Invitrogen), according to the manufacturer's instructions. For primary astrocyte and neuron cultures, $40 \mathrm{ng}$ RNA was assayed directly using the ABI One-step RNA-to-Ct master mix. The results were analyzed by 7500 Fast Real-Time PCR System software (Invitrogen).

Western blot analyses. Consistent amounts of total protein $(2 \mu \mathrm{g}$ for ApoE and synaptophysin assays; $10 \mu \mathrm{g}$ for PSD-95 assay) were loaded on a NuPAGE 4\%-12\% Bis-Tris Gel (Invitrogen) and transferred onto PVDF membrane (Bio-Rad). The membrane was incubated in blocking buffer (Li-Cor) for $1 \mathrm{~h}$ followed by ApoE (sc-8384, Santa Cruz Biotechnology), synaptophysin (ab8049, Abcam), PSD-95 (51-6900, Invitrogen), or GAPDH (sc-25778, Santa Cruz Biotechnology) antibody in blocking buffer $(1: 1000)$ at $4^{\circ} \mathrm{C}$. The membrane was washed with Tris-buffered saline containing $0.05 \%$ Tween 20 followed by incubating with appropriate secondary antibodies conjugated with AlexaFluor-680 (A 21088, Invitrogen), IRDye 800CW (92632212, Li-Cor), or IRDye 680RD (926-68071, Li-Cor) in blocking buffer for $1 \mathrm{~h}$. Then each protein's specific band was visualized using the Odyssey Imaging System (Li-Cor). Specificity of bands was confirmed in tissues from Apoe $\mathrm{KO}$ mice (for ApoE band) and/or by omitting primary antibody incubation. Western blots were performed in multiple gels. To normalize interblot variability, identical samples were loaded in each blot as internal controls, and the density of the internal standard sample (normalized by GAPDH or $\beta$-actin) was used to standardize other samples in multiple blots.

Immunohistochemistry. Mice ( $n=2$ or 3 /group) were perfusion-fixed, and immunohistochemistry was performed for visualization of protein localization, according to the method previously described (Qin et al., 2014). Brains were sectioned coronally in a cryostat (thickness, $40 \mu \mathrm{m}$ ) and incubated overnight with the following primary antibodies: GFAP (astrocytes marker, 1:3000; EMD Millipore), ApoE (1:000; Abcam), MAP-2 (neuronal marker, 1:3000, Abcam), followed by incubation with appropriate secondary antibodies conjugated with AlexaFluor- 488 or -594 (1:200; Invitrogen) for $1 \mathrm{~h}$ at room temperature. Specificity of the staining was confirmed in the brain section from Apoe KO mice (for ApoE) and omitting primary antibody incubation. Sections were washed with PBS between incubations and examined under a florescent microscope or laser scanning confocal microscopy (Carl Zeiss).

Behavior tests. Motor and gait functions were longitudinally assessed by a rotarod (Med Associates) and Noldus Catwalk XT gait analysis system (Noldus Information Technology), as previously reported (Qin et al., 2014). For rotarod test, mice were placed on a rod of rotarod device, which was set to accelerate from 4 to $40 \mathrm{rpm}$ over the course of $5 \mathrm{~min}$. After 1 week of daily pretraining, the latency to fall from the rod was averaged from five trials. For Catwalk, mice were pretrained daily for 2 weeks to cross an illuminated glass walkway 3 consecutive times and then at intervals during the poststroke period. The images from each trial that consisted of 3 consecutive runs were converted into digital signals. Each footprint was classified as a left front (LF), left hind (LH), right front $(\mathrm{RF})$, and right hindpaw (RH). After the classification, a priori selected gaits parameters that are relevant to the kinematics of stroke recovery were analyzed: spatial parameters based on individual paws (mean intensity), relative position between paws (stride length), temporal parameters (swing speed, walk speed), and parameter related to interlimb coordination (regularity index).

Data analyses. Infarct volume and \%HS were reported as mean $\pm 95 \%$ CIs. All other data were reported as mean \pm SEM Gene expression levels from in vivo studies were presented as the $\beta$-actin normalized value according to the formula, Value $=2(\beta$-actin threshold cycle-target gene's threshold cycle). Gene expression levels in in vitro studies were 

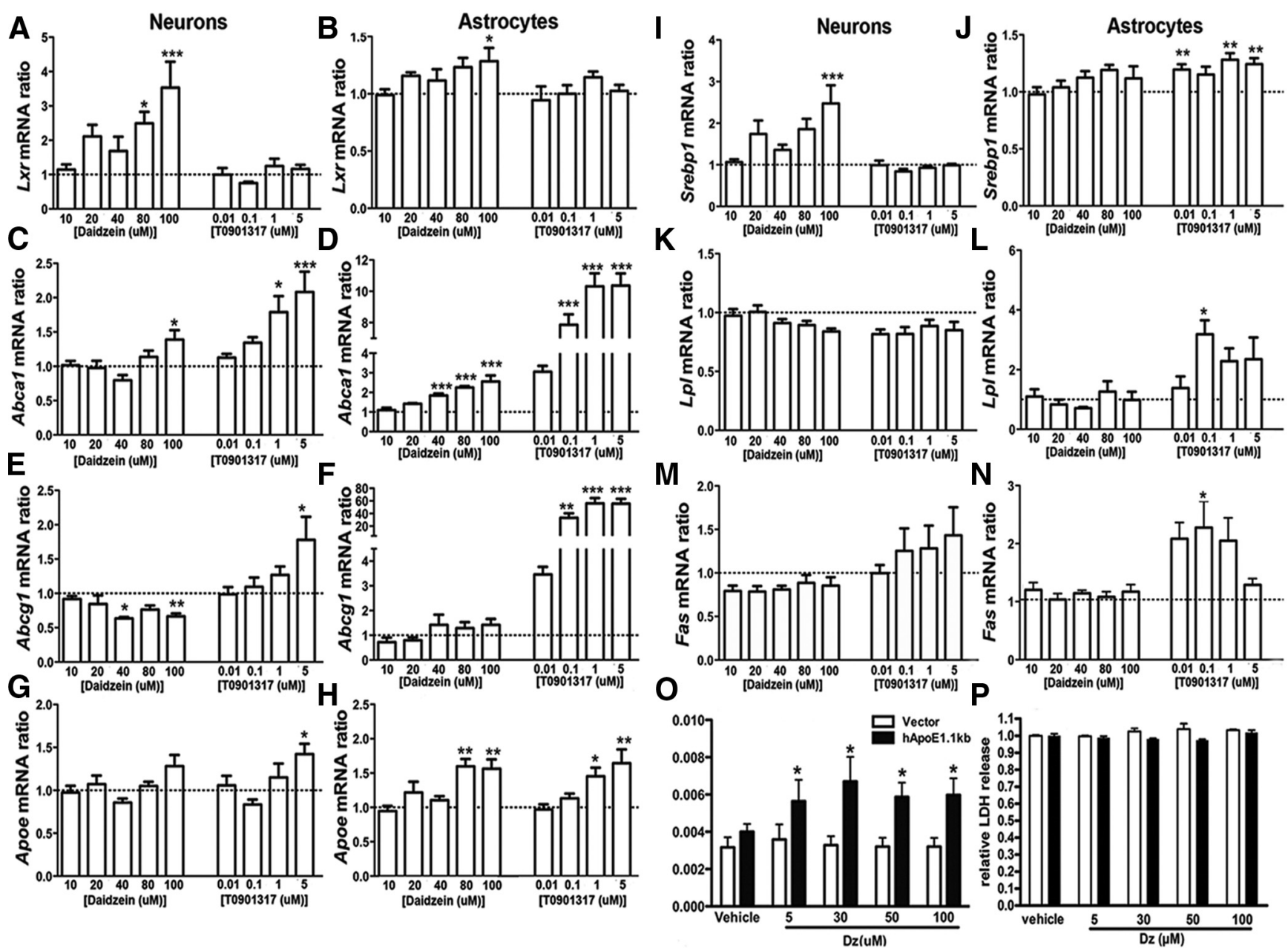

Figure 1. Daidzein increases cholesterol homeostasis program genes in vitro. $A-N$, Gene expression in primary cortical neurons $(A, C, E, G, I, K, M)$ and astrocytes $(B, D, F, H, J, L, N)$ following the incubation of daidzein $(10,20,40,80,100 \mu \mathrm{M})$ or a LXR agonist, T0901317 $(0.01,0.1,1,5 \mu \mathrm{m})$ for $24 \mathrm{~h}$. Lines indicate the expression level of each gene in cultures treated with vehicle for $24 \mathrm{~h}$. ${ }^{*} p<$ 0.05 versus vehicle (one-way ANOVA, Newman-Keuls post hoc test). ${ }^{* *} p<0.01$ versus vehicle (one-way ANOVA, Newman-Keuls post hoc test). ${ }^{* * *} p<0.001$ versus vehicle (one-way ANOVA, Newman-Keuls posthoc test). $\mathbf{O}, \boldsymbol{P}$, Effect of daidzein (Dz) on hAPOE promoter activity indicated by the ratio of firefly/renilla luciferase activities ( $(\mathbf{O})$ and LDH release $(\boldsymbol{P})$ in U373 human glioblastoma cells. $n=6$. Student's $t$ test. ${ }^{*} p<0.05$ versus Vector.

reported relative to control cultures and averaged from three independent experiments.

Statistics. Comparison between two groups was statistically evaluated using Student's $t$ test. Multiple comparisons were made using ANOVA followed by post hoc tests. For gene/protein expression, analyses in cultures and the brain were performed by one-way and two-way ANOVA, respectively, followed by post hoc Newman-Keuls tests. For gait analyses, two-way ANOVA with Bonferroni correction was used. Differences were considered significant at $p<0.05$.

\section{Results}

Daidzein increases Lxr, Apoe, Abcal, and Abcg1 gene expression in vitro

The effect of daidzein on the transcription of genes involved in cholesterol homeostasis, including Lxr and downstream transporters Apoe, Abcal, and Abcg1, was assessed in primary cortical neurons and astrocytes. Daidzein increased expression of $L x r$, a $\operatorname{PPAR} \gamma$-dependent gene, more robustly in neurons than astrocytes (Fig. $1 A, B$ ). In astrocytes, daidzein treatment significantly elevated $A b c a 1$ and Apoe (Fig. $1 D, H$ ), but not $A b c g 1$ mRNA (Fig. $1 F)$. Treating the cultures with T0901317, an LXR agonist, showed expected increases in expression of $L x r$ downstream transporter genes (Fig. $1 \mathrm{C}-\mathrm{H}$ ) but not its own expression (Fig. $1 A, B)$. T0901317 also increased sterol-regulatory element bind- ing proteins-1 (Srebp1) and its target genes, fatty acid synthase (Fas) and lipoprotein lipase ( $L p l)$ in astrocytes (Fig. $1 J, L, N)$. Daidzein increased Srebp1 in neurons (Fig. 1I), without affecting Fas and $L p l$ expression both in neurons and astrocytes (Fig. $1 K-$ $N)$. We further determined transcriptional activity of $A P O E$ in human glioblastoma U373 cells containing a $1.1 \mathrm{~kb}$ of human APOE (hAPOE) promoter-luciferase plasmid (Maloney et al., 2007). Incubation with different concentrations of daidzein, from 5 to $100 \mu \mathrm{M}$, increased $A P O E$ transcriptional activity (Fig. $1 O)$. Lactate dehydrogenase levels in the media in cultures treated with various concentrations of daidzein were not different from vehicle-treated cultures, excluding potential toxicity of daidzein at the concentrations used (Fig. 1P). The findings show that daidzein induces the cholesterol homeostasis genetic program without toxicity and inducing transcription of the lipogenic genes.

\section{Stroke induces $L x r$-downstream transporter gene expression}

To address the relevance of the cholesterol homeostasis genetic program in chronic stroke, we first determined temporal changes in Lxr and transporter Abca1, Abcg1, and Apoe genes in the acute and recovery phase of poststroked brain (Fig. $2 A-D)$. While relatively constant in the contralateral hemisphere, these genes were induced in the stroked hemisphere 
A
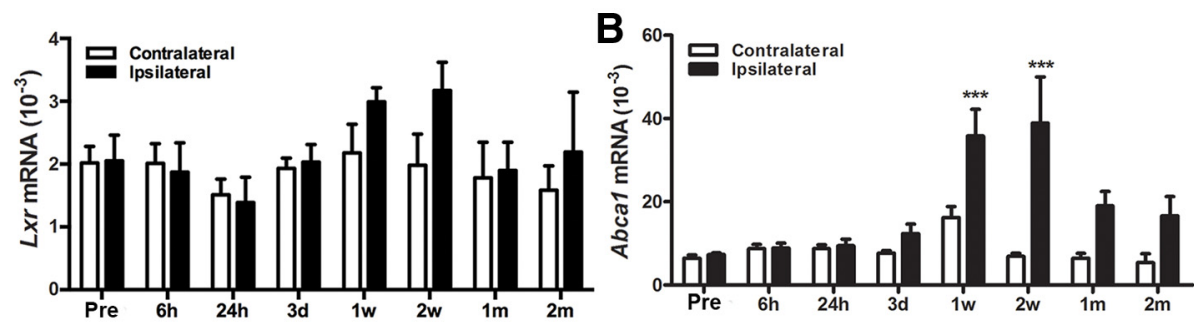

C
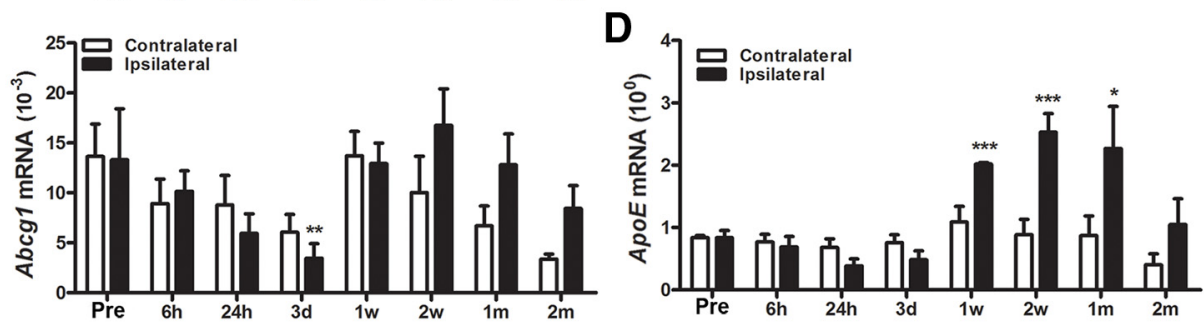

E
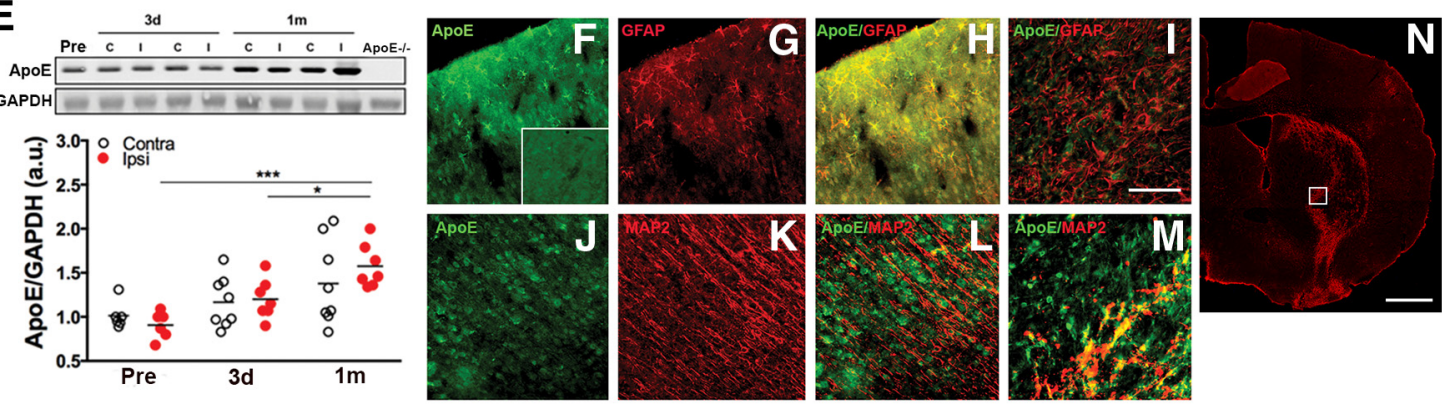

Figure 2. Stroke induces cholesterol homeostasis program in the brain. $\boldsymbol{A}-\boldsymbol{D}$, Temporal gene profiles of $\angle x r(\boldsymbol{A}), A b c a 1(\boldsymbol{B}), A b c g 1(\boldsymbol{C})$, and $A$ poe $(\boldsymbol{D})$ in the poststroke brain at various postischemic time points. mRNA levels in the contralateral and ipsilateral hemispheres were measured without stroke (Pre), and during acute (hours (h) to days (d)), subacute (d to weeks (w)), and long-term recovery (week to months (m)) phases. $y$-axis represents mRNA normalized by actin. ${ }^{*} p<0.05$ versus contralateral (Student's $t$ test). ${ }^{* *} p<0.01$ versus contralateral (Student's $t$ test). ${ }^{* * *} p<$ 0.001 versus contralateral (Student's $t$ test). E, ApoE protein levels in the brain of Pre, $3 \mathrm{~d}$, and 1 month after stroke (cropped images of original blots). Apoe ${ }^{-1-}$, brain tissue from Apoe K0 mice, ${ }^{*} p<$ 0.05 (two-way ANOVA, followed by a Newman-Keuls post hoc test). ${ }^{* * *} p<0.001$ (two-way ANOVA, followed by a Newman-Keuls post hoc test). $\boldsymbol{F}$-M, Immunolocalization of ApoE in 1 month poststroke brain. Double immunofluorescence labeling of ApoE $(\boldsymbol{F})$ with GFAP $(\boldsymbol{G}-\boldsymbol{I})$ or ApoE $(\boldsymbol{J})$ with MAP2 $(\boldsymbol{K}-\boldsymbol{M})$. Merged micrographs in the contralateral cortex $(\boldsymbol{H}, \boldsymbol{L})$, peri-infarct area in the ipsilateral hemisphere $(\boldsymbol{I}, \boldsymbol{M}), \boldsymbol{F}$, Inset, No specific ApoE immunoreactivity in the brains from Apoe K0 mice. $\boldsymbol{N}$, GFAP-stained ipsilateral hemisphere. Square represents the peri-infarct area chosen for I, M. $n=2$. Scale bars: $I, 100 \mu \mathrm{m} ; \boldsymbol{N}, 1 \mathrm{~mm}$.

during 1-4 weeks after stroke, followed by a return to baseline at $\sim 2$ months after stroke. Of these genes, Apoe was the most abundantly expressed cholesterol transporter in the brain. The basal level of Apoe transcripts (Apoe/Actin; $0.84 \pm 0.06, n=$ $4-6)$ was $\sim 50-100$ times higher than those of Abcal $(0.0064 \pm 0.0002)$ and $A b c g 1(0.013 \pm 0.007)$. ApoE protein levels were noticeably elevated at 1 month after stroke but not at day 3 , reflecting corresponding protein expression at this time (Fig. 2E). ApoE protein was predominantly localized in astrocytes in the contralateral (Fig. $2 H$ ) and rarely in the periinfarct region of stroked hemisphere (Fig. $2 I, N$ ). On the other hand, ApoE staining was mostly absent in neurons in the contralateral hemisphere (Fig. $2 L$ ) with some occurrence in the peri-infarct area (Fig. $2 M, N$ ), supporting a reported view on cholesterol transport from astrocytes to neurons during neural repair following CNS injuries (Pfrieger, 2003).

\section{Daidzein increases the stroke-induced cholesterol} homeostasis program without reducing infarct size We initially assessed the effect of daidzein on multiple genes that are involved in cholesterol homeostasis and synaptic remodeling at day 3 after stroke. Ratios of stroke-induced mRNA levels over those in the contralateral hemisphere (ipsilateral/contralateral) in vehicle-treated group showed increased Lxr, Scarbl, Abcal, and Gfap mRNA and the gene induction patterns were similar in daidzein-treated group (Fig. 3A; Table 1). For cholesterol homeostasis genes, we found that stroke significantly increased $L x r$ and Abcal mRNA (Fig. $3 B, C$ ) and decreased in Abcgl and Apoe genes (Fig. $3 D, E$ ). Among these genes, daidzein significantly increased Lxr and Apoe in the ipsilateral hemisphere (Fig. 3B,E). Both treatment groups displayed a similar degree of stroke severity indicated by comparable cerebral blood flow reduction during ischemia (14.6 \pm 1.2 vs $14.1 \pm 0.9, n=25$, not significant) and reperfusion at $10 \mathrm{~min}$ after stroke $(97.2 \pm 6.4 \%$ vs $118.2 \pm 7.3 \%$, not significant). Daidzein treatment neither increased nor decreased infarct size or edema (Fig. $3 F$ ), showing that daidzein has no acute neuroprotective effect.

A possibility of daidzein-induced long-term neuroprotection was assessed in mice treated with daidzein for 1 month. Ratios of stroke-induced mRNA levels against the contralateral hemisphere showed similar increases in Lxr, Scarb1, Abcal, Apoe, Tsp2, and Gfap mRNA in both vehicle and daidzein-treated groups (Fig. 4A; Table 2). Compared with vehicle treatment, daidzein significantly elevated $A b c a 1, A b c g 1$, and Apoe mRNAs at 1 month after stroke (Fig. $4 B-E$ ). For lipogenic genes, daidzein increased stroke-induced Srebpl mRNA without affecting Fas and Lpl expression (Table 2). ApoE protein was also significantly increased at this time (Fig. 4F). There was no difference in expression of the cholesterol homeostasis genes in age-matched sham mice treated with vehicle or daidzein for 1 month (data not shown). Because 
A

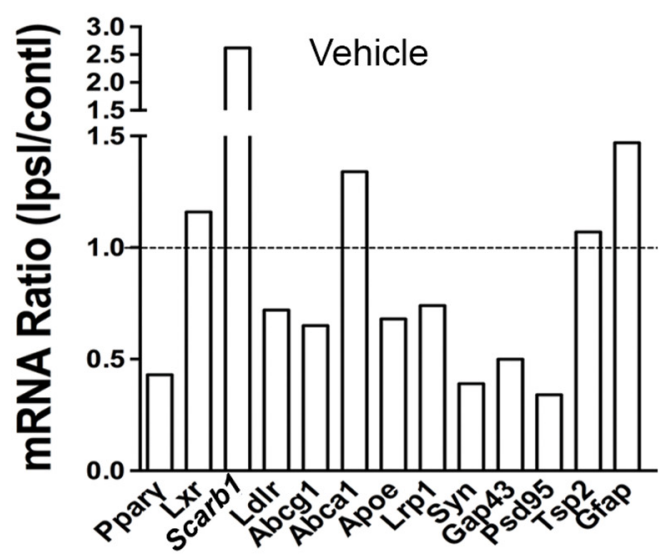

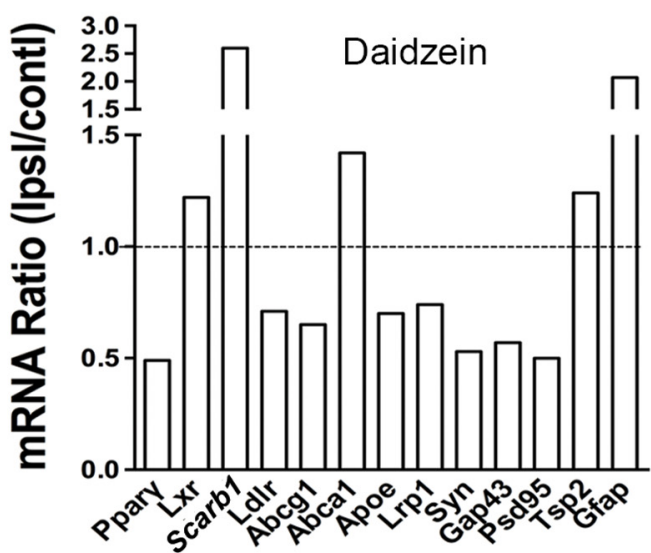

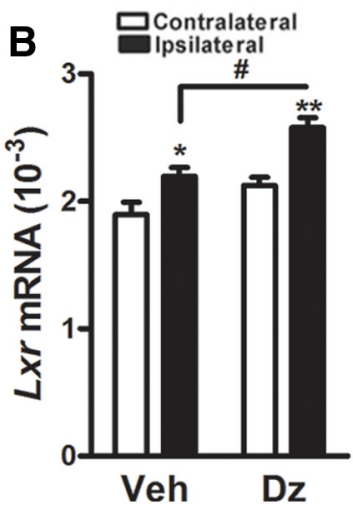

C

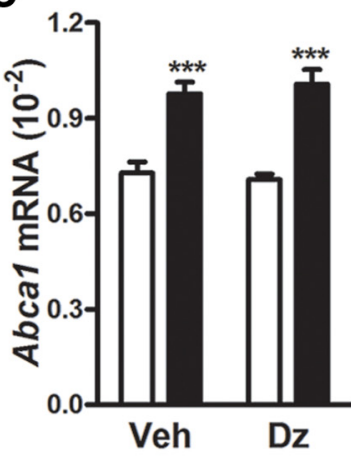

D
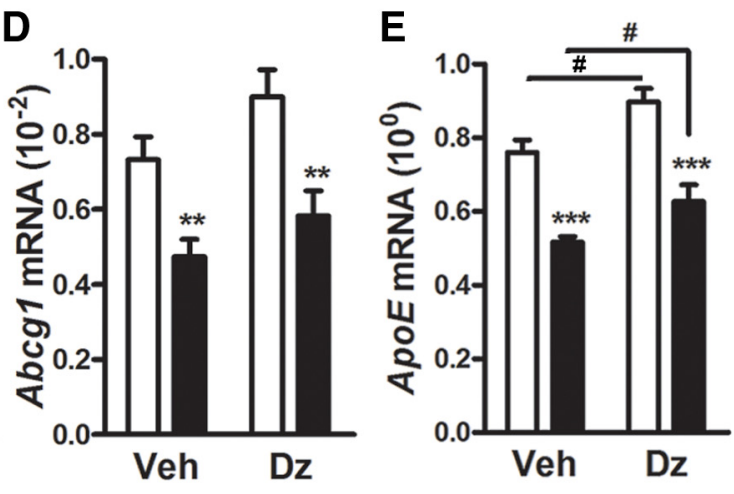

$\mathbf{F}$

Veh
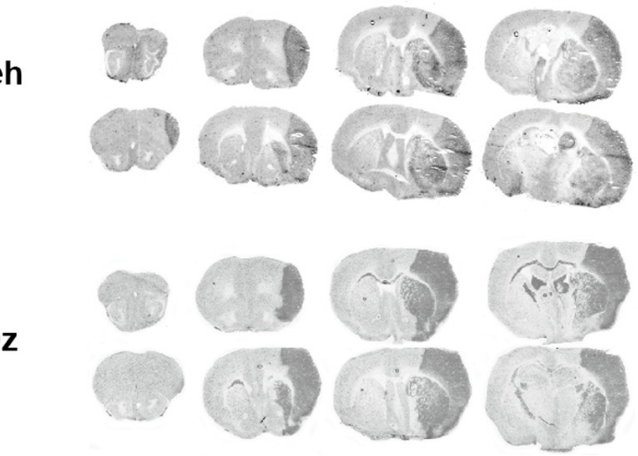

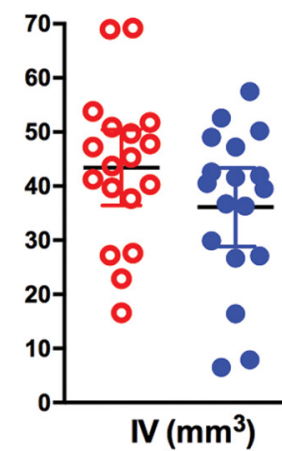

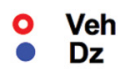

○

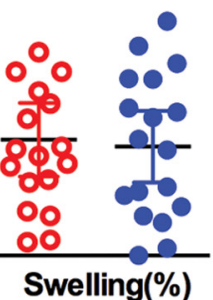

Figure 3. Daidzein increases stroke-induced $L x r$ and Apoe mRNA without affecting acute brain injury. Following 30 min MCA0, mice were treated with daily subcutaneous administration of vehicle (Veh) or daidzein ( $\mathrm{Dz}, 10 \mathrm{mg} / \mathrm{kg}$ ) for $3 \mathrm{~d}$. $\boldsymbol{A}$, Effect of daidzein on stroke-induced cholesterol homeostasis and synaptic plasticity genes in the vehicle (left) and daidzein (right) treated mice at 3 d. Dotted lines indicate mRNA expression in contralateral hemisphere. $y$-axis represents ratios of ipsilateral over contralateral mRNA expression; $n=5$ or $6 . \boldsymbol{B}-\boldsymbol{E}, \operatorname{Lxr}(\boldsymbol{B}), A b c a 1(\boldsymbol{C}), A b c g 1(\boldsymbol{D})$, and Apoe (E) mRNA levels were measured in stroked brain; $n=5$ or 6 . $y$-axis represents mRNA levels normalized by actin. ${ }^{*} p<0.05$ versus contralateral side (effect of stroke) (two-way ANOVA, followed by a Newman-Keuls posthoc test). ${ }^{* *} p<0.01$ versus contralateral side (effect of stroke) (two-way ANOVA, followed by a Newman-Keuls post hoc test). ${ }^{* *} p<0.001$ versus contralateral side (effect of stroke) (two-way ANOVA, followed by a Newman-Keuls post hoc test). ${ }^{*} p<0.05$ versus Veh (effect of treatment) (two-way ANOVA, followed by a Newman-Keuls post hoc test). $\boldsymbol{F}$, Representative brain sections for infarct volume and percentage hemispheric swelling measurement at $3 \mathrm{~d}$ after ischemia (graph, mean $\pm 95 \%$ confidence interval); $n=18 /$ group.

stroke causes atrophy, brain volume representing noninjured tissue, ischemic scar tissue, remaining total ipsilateral tissue, and resorbed tissue (estimated infarct) were analyzed. We found no differences in any of these region volumes (Fig. $4 G$ ), confirming that daidzein-induced cholesterol homeostasis genetic program uncouples with neuroprotection.

\section{Daidzein improves motor/gait function following stroke}

As cholesterol homeostasis is a critical event for injury-induced repair and neural remodeling (Nudo, 2007), we next determined the effect of daidzein on functional recovery. To obtain sensitive and quantifiable functional data, behavior parameters that are biologically meaningful and relevant to the kinematics of stroke patients were chosen a priori for motor/gait function during acute and recovery phases following stroke. Stroke-induced changes in behavior were expressed as a percentage of the preischemia baseline to account for interanimal variability. Stroke caused acute body weight reduction, which returned to baseline $\sim 1$ month in both groups. The acute body weight loss was less in daidzein-treated mice (Fig. 5A). Stroke caused acute and sustained deficits in locomotion in rotarod performance (Fig. 5B) and walking speed (Fig. $5 C$ ), which were improved by daidzein 
Table 1. Gene expression in the brain $3 \mathrm{~d}$ after stroke ${ }^{a}$

\begin{tabular}{|c|c|c|c|c|c|}
\hline & & \multicolumn{2}{|l|}{ Vehicle } & \multicolumn{2}{|l|}{ Daidzein } \\
\hline & & Contralateral & Ipsilateral & Contralateral & Ipsilateral \\
\hline Ppar $\gamma$ & $=$ & $1.20 \mathrm{E}-03 \pm 9.9 \mathrm{E}-05$ & $0.52 \mathrm{E}-03 \pm 6.0 \mathrm{E}-05^{b}$ & $1.41 \mathrm{E}-03 \pm 12.4 \mathrm{E}-05$ & $0.69 \mathrm{E}-03 \pm 16.4 \mathrm{E}-05^{b}$ \\
\hline Lxr & 个 & $1.90 \mathrm{E}-03 \pm 9.7 \mathrm{E}-05$ & $2.20 \mathrm{E}-03 \pm 7.1 \mathrm{E}-05^{b}$ & $2.12 \mathrm{E}-03 \pm 6.3 \mathrm{E}-05$ & $2.58 \mathrm{E}-03 \pm 7.7 \mathrm{E}-05^{b, c}$ \\
\hline Scarb1 & $=$ & $1.83 \mathrm{E}-03 \pm 1.1 \mathrm{E} \pm 04$ & $4.79 \mathrm{E}-03 \pm 2.7 \mathrm{E}-04^{b}$ & $1.57 \mathrm{E}-03 \pm 2.3 \mathrm{E}-04$ & $4.08 \mathrm{E}-03 \pm 6.2 \mathrm{E}-04^{b}$ \\
\hline Ldlr & $=$ & $5.63 \mathrm{E}-03 \pm 7.5 \mathrm{E}-04$ & $4.03 \mathrm{E}-03 \pm 4.9 \mathrm{E}-04$ & $5.44 \mathrm{E}-03 \pm 8.0 \mathrm{E}-04$ & $3.84 \mathrm{E}-03 \pm 5.3 \mathrm{E}-04$ \\
\hline Abcg1 & $=$ & $7.32 \mathrm{E}-03 \pm 6.1 \mathrm{E}-04$ & $4.74 \mathrm{E}-03 \pm 4.6 \mathrm{E}-04^{b}$ & $9.00 \mathrm{E}-03 \pm 7.2 \mathrm{E}-04$ & $5.82 \mathrm{E}-03 \pm 6.7 \mathrm{E}-04^{b}$ \\
\hline Abca1 & $=$ & $7.28 \mathrm{E}-03 \pm 3.5 \mathrm{E}-04$ & $9.77 \mathrm{E}-03 \pm 3.7 \mathrm{E}-04^{b}$ & $7.07 \mathrm{E}-03 \pm 1.8 \mathrm{E}-04$ & $10.07 \mathrm{E}-03 \pm 4.6 \mathrm{E}-04^{b}$ \\
\hline Apoe & 个 & $7.61 \mathrm{E}-01 \pm 3.3 \mathrm{E}-02$ & $5.17 \mathrm{E}-01 \pm 1.5 \mathrm{E}-02^{b}$ & $8.97 \mathrm{E}-01 \pm 3.7 \mathrm{E}-02^{d}$ & $6.27 \mathrm{E}-01 \pm 4.6 \mathrm{E}-02^{b, c}$ \\
\hline Lrp1 & $=$ & $8.99 \mathrm{E}-02 \pm 7.5 \mathrm{E}-03$ & $6.61 \mathrm{E}-02 \pm 5.5 \mathrm{E}-03^{b}$ & $9.52 \mathrm{E}-02 \pm 2.9 \mathrm{E}-03$ & $7.06 \mathrm{E}-02 \pm 6.5 \mathrm{E}-03$ \\
\hline Synaptophysin & $=$ & $2.38 \mathrm{E}-01 \pm 1.1 \mathrm{E}-02$ & $0.92 \mathrm{E}-01 \pm 1.2 \mathrm{E}-02^{b}$ & $2.70 \mathrm{E}-01 \pm 1.7 \mathrm{E}-02$ & $1.44 \mathrm{E}-01 \pm 2.7 \mathrm{E}-02^{b}$ \\
\hline Gap-43 & $=$ & $7.61 \mathrm{E}-02 \pm 3.0 \mathrm{E}-03$ & $3.77 \mathrm{E}-02 \pm 4.1 \mathrm{E}-03^{b}$ & $7.85 \mathrm{E}-02 \pm 4.4 \mathrm{E}-03$ & $4.45 \mathrm{E}-02 \pm 5.5 \mathrm{E}-03^{b}$ \\
\hline Psd-95 & $=$ & $1.50 \mathrm{E}-01 \pm 1.2 \mathrm{E}-02$ & $0.51 \mathrm{E}-01 \pm 0.7 \mathrm{E}-02^{b}$ & $1.47 \mathrm{E}-01 \pm 1.3 \mathrm{E}-02$ & $0.73 \mathrm{E}-01 \pm 1.1 \mathrm{E}-02^{b}$ \\
\hline Gfap & $=$ & $2.57 \mathrm{E}-01 \pm 1.7 \mathrm{E}-02$ & $3.77 \mathrm{E}-01 \pm 1.9 \mathrm{E}-02^{b}$ & $1.93 \mathrm{E}-01 \pm 5.0 \mathrm{E}-02$ & $4.00 \mathrm{E}-01 \pm 4.5 \mathrm{E}-02^{b}$ \\
\hline
\end{tabular}

${ }^{a}$ Data are mean \pm SEM. $=$ and $\uparrow$ indicate no and significant gene changes in the ipsilateral hemisphere by daidzein treatment.

${ }^{b} p<0.05$ versus contralateral (two-way ANOVA and post hoc Newman-Keuls test); $n=5$ or 6 .

$c^{c} p<0.05$ versus ipsilateral of vehicle (two-way ANOVA and post hoc Newman-Keuls test); $n=5$ or 6 .

${ }^{d} p<0.05$ versus contralateral of vehicle (two-way ANOVA and post hoc Newman-Keuls test); $n=5$ or 6 .

(indicated by \#). Daidzein did not show benefit on the regularity index, a measure of interlimb coordination that spontaneously recovered by 2 weeks (Fig. $5 D$ ).

Several gait parameters for individual limbs were assessed in LF, LH, RF, and RH limbs. Following stroke, all four limbs showed sustained impairment in stride length (distance between paw prints). Chronic daidzein administration significantly reduced the deficit in LF, LH, and RH limbs (Fig. 6A). While stroke also caused sustained reduction in swing speed in all limbs in both groups, daidzein attenuated the deficit in RH limb (Fig. 6B). Similar to the regularity index shown in Figure $5 D$, daidzein did not improve mean intensity, another spontaneously recovered parameter (Fig. 6C). Overall, the results showed that daidzein treatment improves motor/gait functions that showed sustained deficit, but not gait parameters that were fully recovered, highlighting the efficacy of daidzein in a clinically meaningful context. The functional benefits of daidzein treatment in the absence of neuroprotection indicate that mechanisms underlying neuroprotection unlikely overlap with recovery/repair processes. In age-matched sham animals, chronic daidzein treatment did not affect the longitudinal gait functions compared with those of vehicle-treated group (data not shown).

\section{ApoE deficiency abolishes daidzein-enhanced motor/gait function in stroke}

As ApoE is the most abundant cholesterol transporter that was elevated by daidzein in vivo, we addressed the importance of daidzein-induced ApoE upregulation in functional recovery in Apoe-knock-out (Apoe KO) mice. Stroke resulted in acute body weight losses with subacute normalization by 2 weeks in vehicletreated Apoe KO mice. Chronic daidzein treatment did not attenuate acute body weight loss or improve rotarod performance (Fig. $7 A, B$ ). Daidzein also provided no functional benefits in gait functions (Fig. 7C-F). The only treatment effect (indicated by \#) observed in Apoe $\mathrm{KO}$ mice was the mean intensity in right $\mathrm{RH}$, where daidzein treatment resulted in a greater deficit (Fig. $7 G$ ). Estimation of infarct volume by subtracting the ipsilateral from contralateral volumes at 1 month after ischemia showed no difference between the groups (Veh vs Dz, $20.2 \pm 3.8$ vs $25.8 \pm 4.0$ $\mathrm{mm}^{3}$, not significant, $n=13-14$ /group), confirming no detectable effect of daidzein on modulating infarct size. Treating Apoe $\mathrm{KO}$ mice with daidzein increased $L x r$ and Abcal gene expression at 1 month after stroke, showing that the absence of ApoE does not interfere with other cholesterol homeostasis genetic programs (Fig. $7 \mathrm{H}-\mathrm{J}$ ). Therefore, the findings suggest that daidzeininduced ApoE upregulation is a critical component in fostering functional recovery in chronic stroke.

\section{ApoE is necessary for daidzein-induced synaptophysin expression in chronic stroke}

We then determined whether the daidzein-induced ApoE upregulation is necessary for induction of synaptic elements after stroke. Chronic daidzein treatment in C57 mice selectively increased synaptophysin mRNA without altering Psd-95 at 1 month after stroke (Fig. $8 A, B$ ). Further analyses between the presynaptic and postsynaptic elements in C57 mice showed significant correlations between them in both hemispheres regardless of treatments (Fig. 8E,F). Notably, daidzein resulted in higher expression of synaptophysin at a given Psd-95 level in the ipsilateral hemisphere with a significant slope difference between the groups $(p<0.001$; Fig. $8 F)$, showing selective elevation of the presynaptic gene. Accordingly, there was a selective increase in stroke-induced synaptophysin protein in the daidzein-treated group (Fig. 8I). Compared with C57 mice, Apoe KO mice showed an overall reduction of synaptophysin mRNA expression in both hemispheres (C57 vs Apoe KO, Contralateral, $0.19 \pm 0.02$ vs $0.07 \pm 0.04$; Ipsilateral, $0.18 \pm 0.09$ vs $0.06 \pm$ $0.0, n=8-10, p<0.001$ ) and $P s d-95$ expression (C57 vs Apoe $\mathrm{KO}$, Contralateral, $0.10 \pm 0.008$ vs $0.078 \pm 0.004$; Ipsilateral $0.099 \pm 0.006$ vs $0.064 \pm 0.008, n=8-10, p<0.05$ ) (Fig. $8 C, D)$. Daidzein treatment further reduced synaptophysin and Psd-95 gene expression in Apoe KO mice (Fig. 8C,D). Synaptophysin and Psd-95 mRNA levels were significantly correlated in both hemispheres regardless of treatment (Fig. $8 G, H$ ). Unlike C57 mice shown in Figure 8F, I, the daidzein-induced selective elevation of synaptophysin gene and protein in the stroked hemisphere was absent in ApoE deficiency (Fig. $8 \mathrm{H}, \mathrm{J})$. Together, the results showed that ApoE is necessary for daidzein-induced synaptophysin expression in chronic stroke.

\section{Discussion}

Injury-induced repair and remodeling occur during critical periods following stroke. These processes provide a temporal window in which augmentation of molecular and synaptic changes can lead to behavioral adaptation/recovery. The current work identified daidzein as an enhancer of the genetic program governing 
A
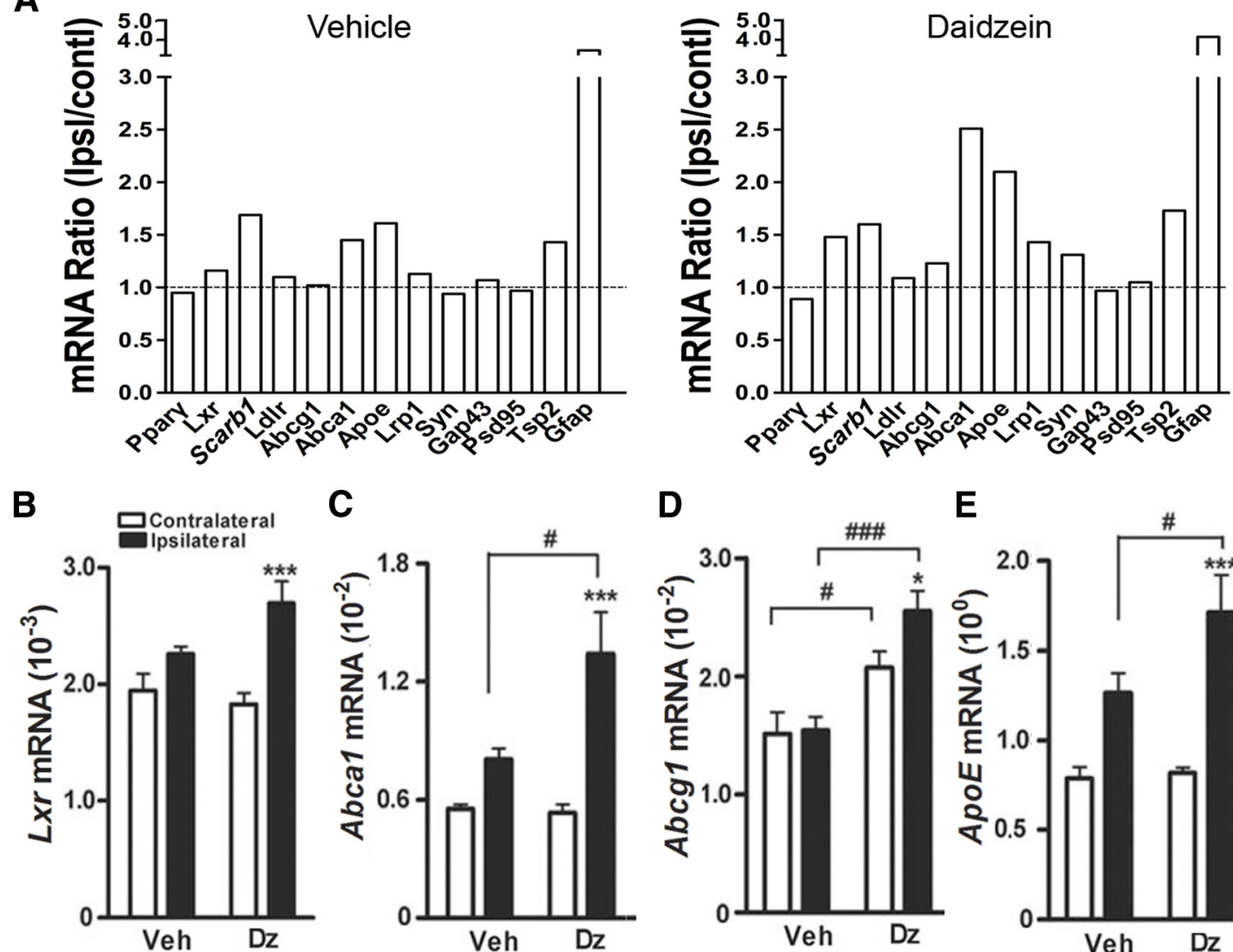

C

D

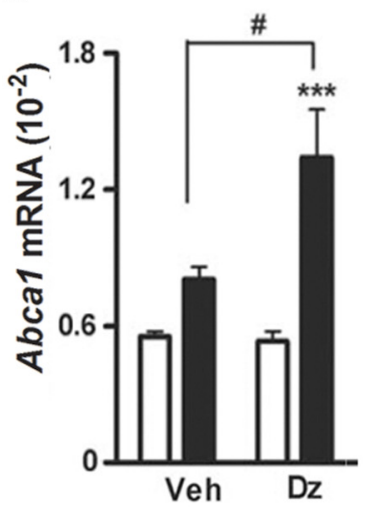

E
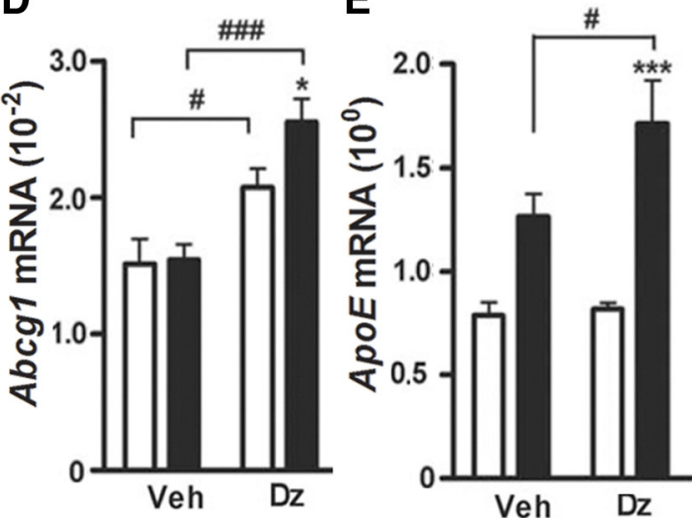

$\mathbf{F}$
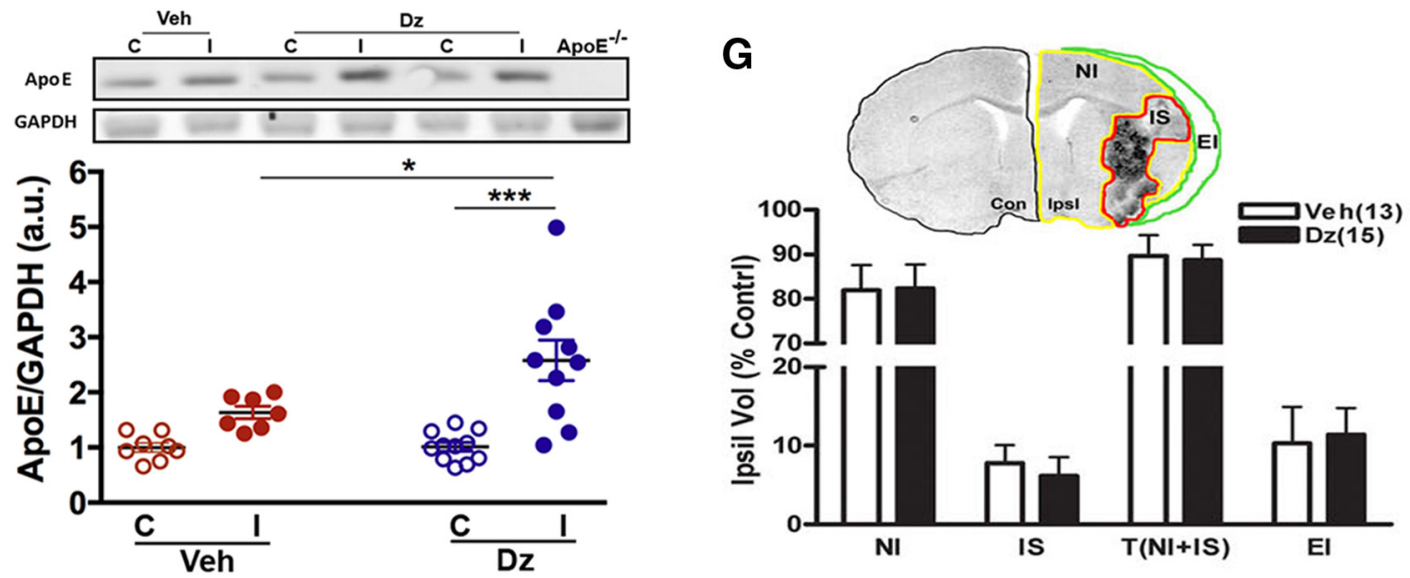

Figure 4. Daidzein increases stroke-induced cholesterol homeostasis genes at 1 month without neuroprotection. Following 30 min MCA0, mice were treated with daily subcutaneous administration of vehicle (Veh) or daidzein (Dz, $10 \mathrm{mg} / \mathrm{kg}$ ) up to $7 \mathrm{~d}$ and then every other day up to 1 month. $A$, Effect of daidzein on stroke-induced cholesterol homeostasis and synaptic plasticity genes in the brain at 1 month after stroke in mice chronically treated with vehicle (left) and daidzein (right). Dotted lines indicate mRNA expression in contralateral hemisphere. $y$-axis represents ratios of ipsilateral over contralateral mRNA expression; $n=5$ or $6 . \boldsymbol{B}-\boldsymbol{E}, L x r(\boldsymbol{B}), A b c a 1(\boldsymbol{C}), A b c g 1(\boldsymbol{D})$, and Apoe $(\boldsymbol{E})$ mRNA levels were measured in the stroked brain at 1 month after MCA0; $n=8-11, \boldsymbol{F}$, ApoE protein levels in vehicle (Veh)- or daidzein (Dz)- treated brain at 1 month after stroke. Apoe ${ }^{-1-}$, brain tissue from Apoe K0 mice. ${ }^{*} p<0.05$ versus contralateral side (two-way ANOVA, followed by a Newman-Keuls post hoc test). ${ }^{* *} p<0.01$ versus contralateral side (two-way ANOVA, followed by a Newman-Keuls post hoc test). ${ }^{* * *} p<0.001$ versus contralateral side (two-way ANOVA, followed by a Newman-Keuls post hoc test). ${ }^{*} p<0.05$ versus Veh ipsilateral (two-way ANOVA, followed by a Newman-Keuls post hoc test). ${ }^{\# \# \# ~}<0.001$ versus Veh ipsilateral (two-way ANOVA, followed by a Newman-Keuls post hoc test). G, Assessment of tissue volume at 1 month after ischemia. NI, Noninjured tissue (yellow); IS, ischemic scar tissue (red); $\mathrm{T}$, total ipsilateral tissue (NI + IS); El, estimated infarct tissue calculated by subtracting total ipsilateral volume from total contralateral volume (i.e., difference between the hemispheres, green).

cholesterol homeostasis and a potential stroke recovery agent. The daidzein-induced benefits include increased expression of genes that regulate the cholesterol homeostasis both in cultures and poststroke brain, and enhanced motor/gait function during the chronic recovery phase. Notably, the study revealed that daidzein-induced ApoE upregulation is essential for enhancing motor/gait functions and upregulation of synaptophysin, a presynaptic element.
Literature shows that isoflavones, including daidzein, inhibits HMG-CoA reductase, an enzyme for cholesterol biosynthesis (Sung et al., 2004; Jung and Kim, 2013). Because daidzein was known to activate PPAR $\gamma$, an upstream transcription factor of $L x r$, the study focused on the effect of daidzein on expression of the genes involved in cholesterol homeostasis rather than its biosynthetic pathway. Not only $L x r$ and the downstream target transporters were elevated in vitro, daidzein also elevated the cho- 
Table 2. Gene expression in the brain 1 month after stroke ${ }^{a}$

\begin{tabular}{|c|c|c|c|c|c|}
\hline & & Vehicle & & Daidzein & \\
\hline & & Contralateral & Ipsilateral & Contralateral & Ipsilateral \\
\hline Ppar $\gamma$ & $=$ & $1.50 \mathrm{E}-03 \pm 1.6 \mathrm{E}-04$ & $1.43 \mathrm{E}-03 \pm 1.1 \mathrm{E}-04$ & $1.61 \mathrm{E}-03 \pm 0.7 \mathrm{E}-04$ & $1.43 \mathrm{E}-03 \pm 1.5 \mathrm{E}-04$ \\
\hline Lxr & $=$ & $1.95 \mathrm{E}-03 \pm 1.5 \mathrm{E}-04$ & $2.26 \mathrm{E}-03 \pm 0.7 \mathrm{E}-04$ & $1.83 \mathrm{E}-03 \pm 1.0 \pm 04$ & $2.70 \mathrm{E}-03 \pm 1.8 \mathrm{E} \pm 04^{b}$ \\
\hline Scarb1 & $=$ & $1.26 \mathrm{E}-03 \pm 0.8 \mathrm{E} \pm 04$ & $2.13 \mathrm{E}-03 \pm 2.6 \mathrm{E}-04^{b}$ & $1.35 \mathrm{E}-03 \pm 1.1 \mathrm{E}-04$ & $2.16 \mathrm{E}-03 \pm 1.4 \mathrm{E}-04^{b}$ \\
\hline Ldlr & $=$ & $4.65 \mathrm{E}-03 \pm 4.3 \mathrm{E}-04$ & $5.11 \mathrm{E}-03 \pm 5.6 \mathrm{E}-04$ & $4.78 \mathrm{E}-03 \pm 4.9 \mathrm{E}-04$ & $5.21 \mathrm{E}-03 \pm 3.3 \mathrm{E}-04$ \\
\hline Abcg1 & 个 & $1.51 \mathrm{E}-02 \pm 1.8 \mathrm{E}-03$ & $1.54 \mathrm{E}-02 \pm 1.2 \mathrm{E}-03$ & $2.07 \mathrm{E}-02 \pm 1.4 \mathrm{E}-03^{d}$ & $2.55 \mathrm{E}-02 \pm 1.7 \mathrm{E}-03^{b, c}$ \\
\hline Abca1 & $\Uparrow$ & $5.53 \mathrm{E}-03 \pm 2.4 \mathrm{E}-04$ & $8.04 \mathrm{E}-03 \pm 5.7 \mathrm{E}-04$ & $5.34 \mathrm{E}-03 \pm 4.4 \mathrm{E}-04$ & $13.41 \mathrm{E}-03 \pm 21.1 \mathrm{E}-04^{b,}$ \\
\hline Apoe & $\Uparrow$ & $7.87 \mathrm{E}-01 \pm 6.4 \mathrm{E}-02$ & $11.65 \mathrm{E}-01 \pm 5.4 \mathrm{E}-02$ & $8.17 \mathrm{E}-01 \pm 3.2 \mathrm{E}-02$ & $17.12 \mathrm{E}-01 \pm 21.2 \mathrm{E}-02^{b, c}$ \\
\hline Lrp1 & $=$ & $4.22 \mathrm{E}-02 \pm 4.1 \mathrm{E}-03$ & $4.76 \mathrm{E}-02 \pm 3.8 \mathrm{E}-03$ & $4.02 \mathrm{E}-02 \pm 3.1 \mathrm{E}-03$ & $5.76 \mathrm{E}-02 \pm 4.4 \mathrm{E}-03^{b}$ \\
\hline Synaptophysin & $\Uparrow$ & $1.96 \mathrm{E}-01 \pm 2.0 \mathrm{E}-02$ & $1.84 \mathrm{E}-01 \pm 1.1 \mathrm{E}-02$ & $1.82 \mathrm{E}-01 \pm 0.9 \mathrm{E}-02$ & $2.38 \mathrm{E}-01 \pm 1.1 \mathrm{E}-02^{b, c}$ \\
\hline Gap-43 & $\Downarrow$ & $1.67 \mathrm{E}-01 \pm 9.1 \mathrm{E}-03$ & $1.79 \mathrm{E}-01 \pm 4.8 \mathrm{E}-03$ & $1.40 \mathrm{E}-01 \pm 13.3 \mathrm{E}-03$ & $1.36 \mathrm{E}-01 \pm 5.4 \mathrm{E}-03^{\mathrm{C}}$ \\
\hline Psd-95 & $=$ & $1.02 \mathrm{E}-01 \pm 9.2 \mathrm{E}-03$ & $0.99 \mathrm{E}-01 \pm 6.8 \mathrm{E}-03$ & $0.98 \mathrm{E}-01 \pm 3.9 \mathrm{E}-03$ & $1.03 \mathrm{E}-01 \pm 5.7 \mathrm{E}-03$ \\
\hline Gfap & $\Uparrow$ & $6.70 \mathrm{E}-02 \pm 4.0 \mathrm{E}-03$ & $23.19 \mathrm{E}-02 \pm 23.7 \mathrm{E}-03^{b}$ & $8.07 \mathrm{E}-02 \pm 7.4 \mathrm{E}-03$ & $33.46 \mathrm{E}-02 \pm 45.4 \mathrm{E}-03^{b,}$ \\
\hline Fas & $=$ & $2.37 \mathrm{E}-02 \pm 2.3 \mathrm{E}-03$ & $2.19 \mathrm{E}-02 \pm 1.7 \mathrm{E}-03$ & $2.27 \mathrm{E}-02 \pm 1.1 \mathrm{E}-03$ & $2.44 \mathrm{E}-02 \pm 1.1 \mathrm{E}-03$ \\
\hline Lpl & $=$ & $1.06 \mathrm{E}-02 \pm 6.0 \mathrm{E}-04$ & $1.31 \mathrm{E}-02 \pm 2.2 \mathrm{E}-03$ & $1.01 \mathrm{E}-02 \pm 7.3 \mathrm{E}-04$ & $1.62 \mathrm{E}-02 \pm 2.2 \mathrm{E}-03^{b}$ \\
\hline Srebp1 & $\Uparrow$ & $1.02 \mathrm{E}-03 \pm 9.1 \mathrm{E}-05$ & $1.10 \mathrm{E}-03 \pm 10.1 \mathrm{E}-05$ & $1.00 \mathrm{E}-03 \pm 5.2 \mathrm{E}-05$ & $1.45 \mathrm{E}-03 \pm 9.6 \mathrm{E}-05^{b, c}$ \\
\hline
\end{tabular}

${ }^{a}$ Data are mean \pm SEM. $=$, , and $\Downarrow$ indicate no and significant gene changes in the ipsilateral hemisphere by daidzein treatment.

${ }^{b} p<0.05$ versus contralateral (two-way ANOVA and post hoc Newman-Keuls test); $n=8-11$.

${ }^{c} p<0.05$ versus ipsilateral of vehicle (two-way ANOVA and post hoc Newman-Keuls test); $n=8-11$.

${ }^{d} p<0.05$ versus contralateral of vehicle (two-way ANOVA and post hoc Newman-Keuls test); $n=8-11$.

A

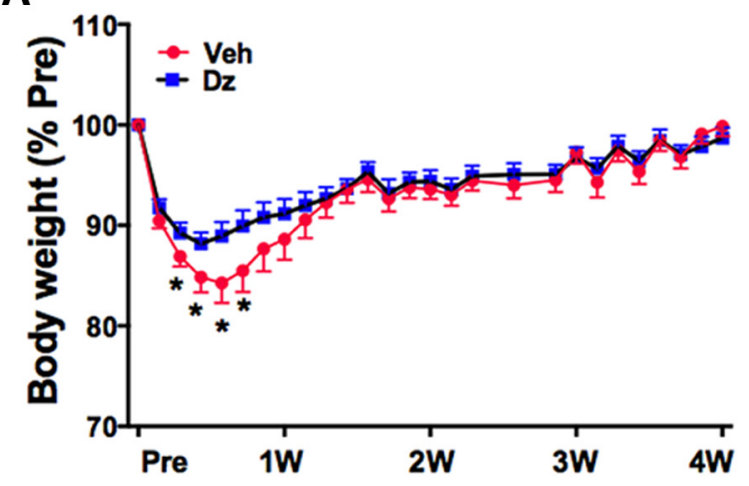

C

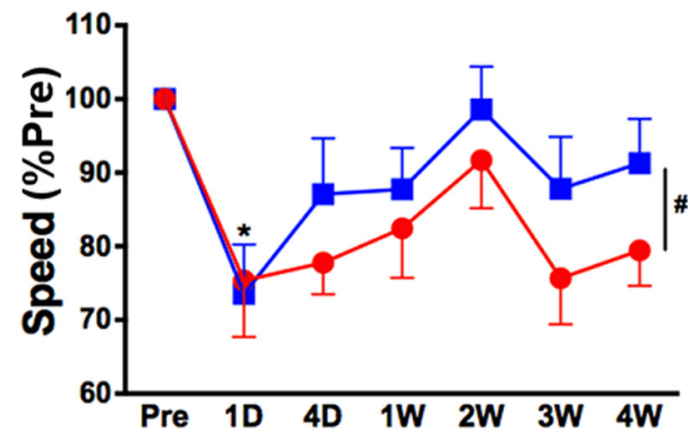

B

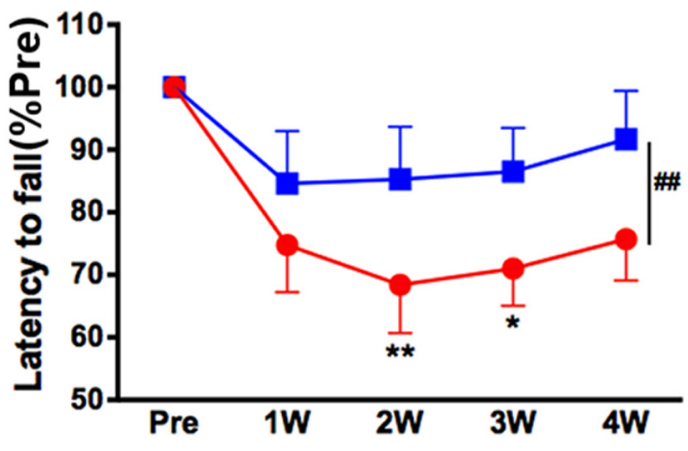

D

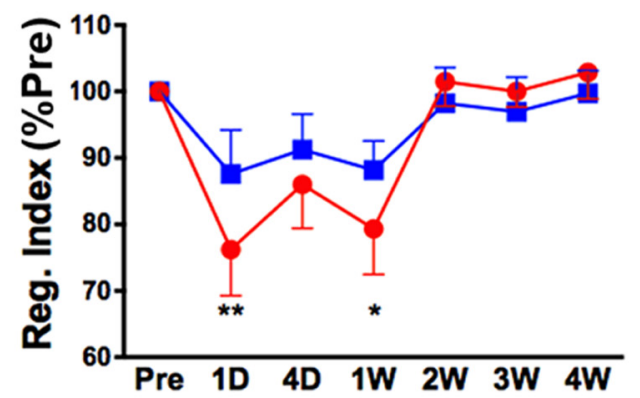

Figure 5. Daidzein reduces stroke-induced body weight loss and improves behaviors. Longitudinal body weight measurement and behavior test were performed in vehicle (Veh) or daidzein (Dz)-treated 57 mice during acute and recovery phases. $A$, Percentage changes of body weight following ischemia. The stroke-induced body weight reduction was attenuated in daidzein-treated mice during a critical period ( $3-6 \mathrm{~d}$ after stroke); $n=22 .{ }^{*} p<0.05$ versus Veh. $\boldsymbol{B}$, Rotarod performance before (pre) and during the 4 week (w) postischemic period, latency to fall measured in seconds; $n=9-11 /$ group. $\boldsymbol{C}, \boldsymbol{D}$, Catwalk gait analyses: walk speed, the average speed expressed in distance units per second (C). Regularity index, a parameter to gauge the degree of interlimb coordination (D). All behavior results are presented as percentage of preischemic baseline (\% Pre, mean \pm SEM); $n=22$ or 23/group. ${ }^{*} p<0.05$ (two-way ANOVA with post hoc Bonferroni tests). ${ }^{* *} p<0.01$ versus Pre (effect of stroke) (two-way ANOVA with posthoc Bonferroni tests). ${ }^{\#} p<0.05$, Veh versus Dz (effect of treatment) (two-way ANOVA with post hoc Bonferronitests). ${ }^{\# \#} p<0.01$, Veh versus $\mathrm{Dz}$ (effect of treatment) (two-way ANOVA with post hoc Bonferroni tests).

lesterol homeostasis genetic program in postischemic brain while several other genes were relatively unaffected (Tables 1, 2). As LXR is an important regulator of cholesterol and lipid metabolism, the augmentation of cholesterol transporter expression via LXR agonists was used to treat animal models of atherosclerosis and stroke (Terasaka et al., 2003; Chen et al., 2010). However, the
LXR-directed approach stimulates transcription of Srebp 1 and its target genes Fas and Lpl. FAS and LPL are linked to the synthesis of fatty acids and triglycerides, resulting in hypertriglyceridemia and hepatic steatosis (Grefhorst et al., 2002; Chisholm et al., 2003). Thus, an optimal therapeutic strategy would be to selectively activate cholesterol efflux pathways without stimulating 

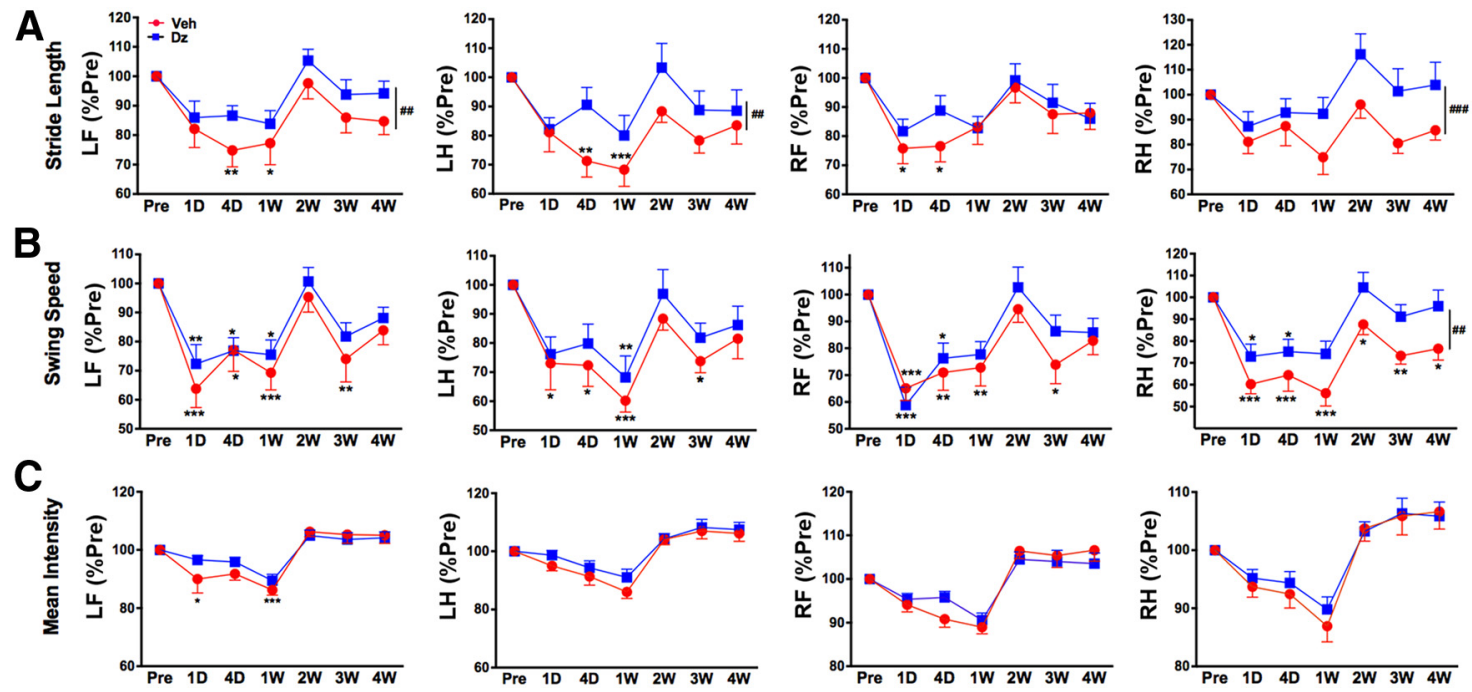

Figure 6. Daidzein improves gait functions. Longitudinal behavior tests were performed in vehicle (Veh) or daidzein (Dz)-treated C57 mice during acute and recovery phases. $\boldsymbol{A}-\boldsymbol{C}$, Gait parameters for individual limb in LF, LH, RF, and RH limbs. Stride length $(\boldsymbol{A})$, swing speed $(\boldsymbol{B})$, and mean intensity ( $\boldsymbol{C}$ ). All behavior results are presented as percentage of preischemic baseline (\% Pre, mean \pm SEM); $n=22$ or 23/group. ${ }^{*} p<0.05$ (tw0-way ANOVA with post hoc Bonferroni tests). ${ }^{* *} p<0.01$ (two-way ANOVA with post hoc Bonferroni tests). ${ }^{* * *} p<0.001$ versus Pre (effect of stroke) (two-way ANOVA with post hoc Bonferroni tests). ${ }^{\# \#} p<0.01$, Veh versus Dz (effect of treatment) (two-way ANOVA with post hoc Bonferroni tests). ${ }^{\# \# \# ~} p<0.001$, Veh versus Dz (effect of treatment) (two-way ANOVA with post hoc Bonferroni tests).

genes linked to lipogenesis (Kratzer et al., 2009). Compared with T0901317, which upregulated Srebp1, Fas, and Lpl transcription in primary astrocytes, daidzein increased Srebp1 transcription without affecting the induction of $L p l$ and Fas genes in vitro (Fig. 1) and in the postischemic brain (Table 2). These findings suggest a potential advantage of daidzein over T0901317 for chronic use in stroke recovery.

The daidzein-induced functional benefits occurred in the absence of neuroprotection. Our previous in vitro data and literature suggested that daidzein, which has years of use in humans, could possibly be neuroprotective and neurorestorative (Ma et al., 2010; Hurtado et al., 2012). However, our current detailed in vivo studies showed that while daidzein enhanced functional recovery, it neither increased nor decreased infarct size, consistent with a study in rats (Stout et al., 2013). The dissociation of functional recovery from neuroprotection indicates the presence of repair process mechanisms that may be distinct from mechanisms that underlie acute pathology/protection. The stagespecific mechanisms reflect the anatomical distinction of the tissues involved in different stages of chronic stroke. While acute pathology involves the ipsilateral hemisphere, functional recovery is thought to require plasticity from noninjured tissues around the infarct and the contralateral hemisphere (Zeiler et al., 2013; Qin et al., 2014). It is noteworthy that the same drug and/or target may respond differently depending on the context of poststroke stages. For example, whereas an agent that inhibits strokeinduced excessive tonic inhibition (net effect of excitation) enhances stroke recovery, the treatment, if given too early (i.e., $<3 \mathrm{~d}$ after stroke), exacerbates acute stroke injury (Clarkson et al., 2010). Thus, agents such as daidzein would allow treatment at an early poststroke stage and provide a wider treatment window for subsequent functional enhancement.

In the current study, daidzein treatment was initiated at the early reperfusion period and continuously administered for 1 month. Several pharmacokinetic studies of chronic daidzein treatment in both humans and rodents have shown increased concentration of isoflavones in body fluids and tissues. With a half-life of $\sim 6 \mathrm{~h}$ in humans and $12 \mathrm{~h}$ in rodents (King and
Bursill, 1998; Coldham and Sauer, 2000), chronic daidzein administration was shown to be safe in clinical trials at a dose of $0.5-1 \mathrm{mg} / \mathrm{kg} / \mathrm{d}$ for 6 months (NCT00951912) or 12 months (NCT01463436). Although the dose used in this study in mice was higher $(5-10 \mathrm{mg} / \mathrm{kg} / \mathrm{d})$ and the treatment duration was shorter ( 1 month) than that used in the above clinical studies, it was within the range of other rodent studies $(0.1-50 \mathrm{mg} /$ kg/d) (Rivera et al., 2013; Soumyakrishnan et al., 2014). Importantly, we found that chronic daidzein administration did not increase injury size and hemispheric swelling (Figs. 3F, $4 G)$. The absence of the adverse stroke outcomes in mice together with no evident toxicity in cultures (Fig. 1P) supports safety of daidzein for early and long-term use in chronic stroke.

Analysis of the motor/gait function in C57 mice revealed two sets of behaviors that spontaneously recovered and ones with sustained impairments (Figs. 5, 6). Daidzein improved the behaviors that showed sustained deficits (e.g., rotarod, speed, stride length, and swing speed). On the other hand, the literature indicates that unilateral stroke induces deficits in the limbs of both sides, which has been described in rodent and human (Schaefer et al., 2009; Darling et al., 2011; Pandian and Arya, 2013; Qin et al., 2014). The observations suggest that the ipsilesional side was not "nonaffected" but rather "less affected." The underlying mechanism that accounts for the acute bilateral deficits may include plastic changes in the intact hemisphere and disturbed interhemispheric connectivity, probably due to the ongoing injury in the affected hemisphere that might be involved in the functional impairments in the unaffected limbs (Gonzalez et al., 2004; van Meer et al., 2010). Individual gait assessment in this study revealed that the stroke-induced bilaterally deficits and daidzein treatment resulted in bilateral enhancement (Fig. 6). Because animals were subjected to unilateral right MCAO, improved function in the less affected limb (e.g., RH) suggests a potential role of the contralesional hemisphere in functional recovery (Qin et al., 2014). Relevantly, we observed that daidzein increased Apoe mRNA at $3 \mathrm{~d}$ in the contralateral hemisphere (Fig. $3 E$; Table 1), suggesting an intriguing possibility that this early rise in Apoe 
A
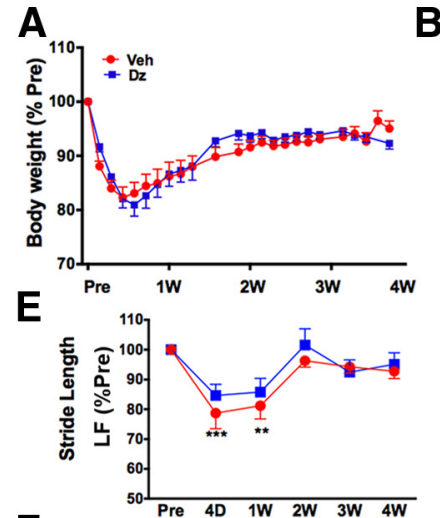

$\mathbf{F}$

G
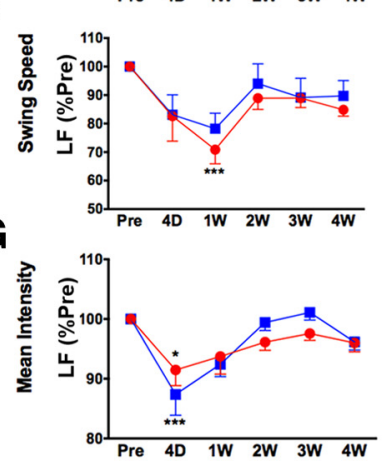

H

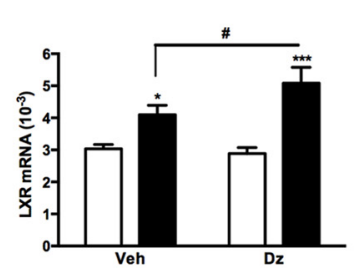

B

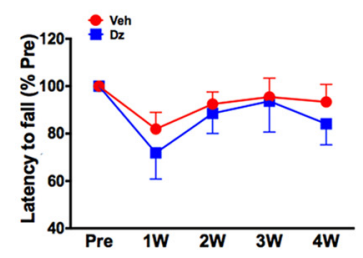

C

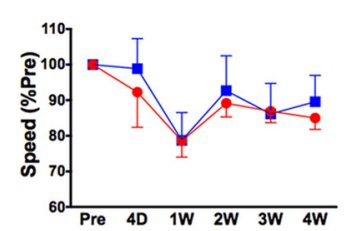

D

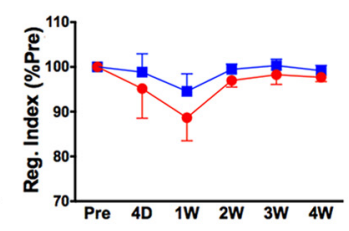

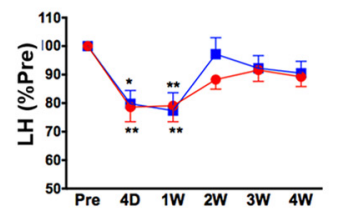
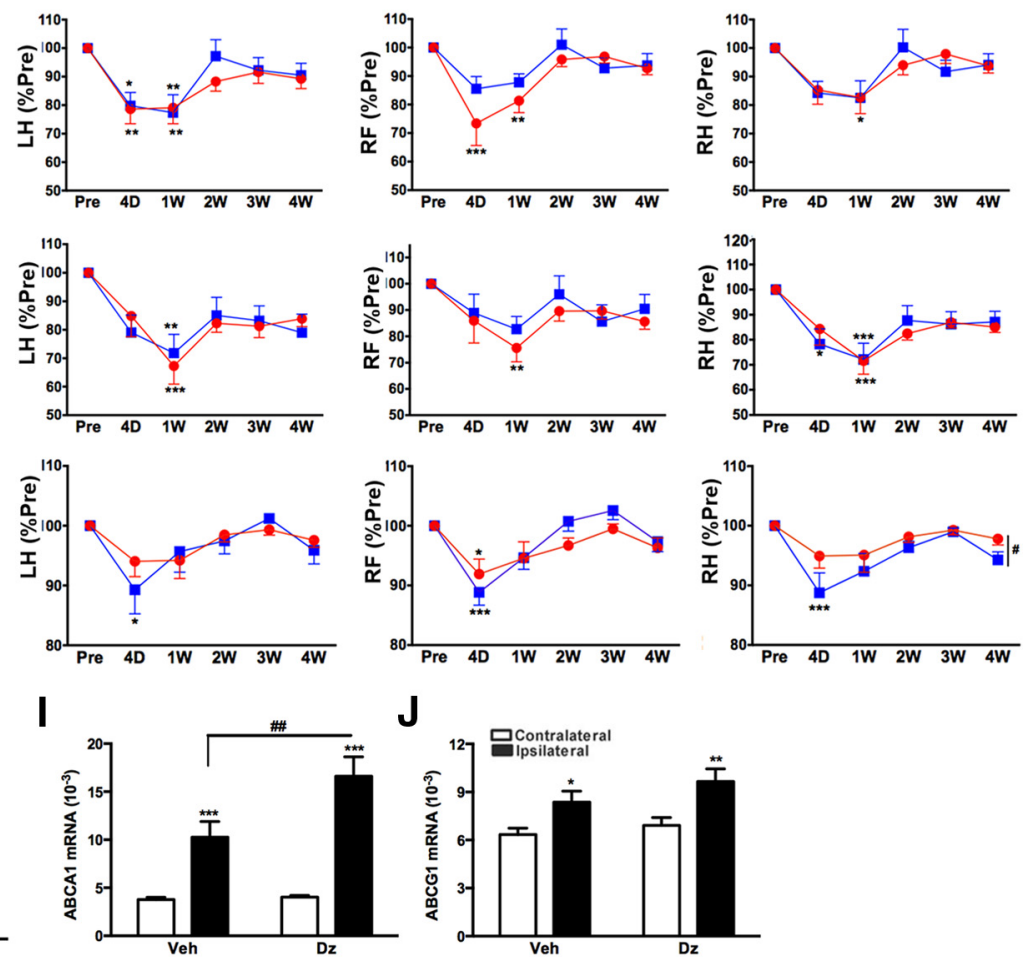

$J$

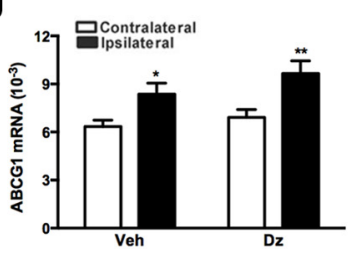

Figure 7. Daidzein-induced functional benefits are absent in ApoE deficiency. Longitudinal behavior test results in vehicle (veh) and daidzein (Dz)-treated Apoe K0 mice during acute and chronic recovery phases. $A$, Percentage changes of body weight following ischemia. Note the similar weight reduction in both groups during a critical period ( $3-6 \mathrm{~d}$ poststroke); $n=$ $10-12 /$ group. $\boldsymbol{B}$, Rotarod performance before (pre) and during the postischemic period up to 4 weeks (w), latency to fall measured in seconds; $n=11 /$ group. $\boldsymbol{C}, \boldsymbol{D}$, Catwalk gait analyses: Walk speed, the average speed expressed in distance units per second (C). Regularity index, a parameter to gauge the degree of interlimb coordination (D). $\boldsymbol{E}-\mathbf{G}$, ( atwalk gait parameters for individual limb in LF, LH, RF, and RH. Stride length $(\boldsymbol{E})$, swing speed $(\boldsymbol{F})$, and mean intensity $(\boldsymbol{G})$. All behavior results are presented as percentage of preischemic baseline $(\%$ Pre, mean \pm SEM); $n=10-13$ group for gait analysis. ${ }^{*} p<0.05$ versus Pre (effect of stroke) (two-way ANOVA with post hoc Bonferroni tests). ${ }^{* *} p<0.01$ versus Pre (effect of stroke) (two-way ANOVA with post hoc Bonferroni tests). ${ }^{* * *} p<0.001$ versus Pre (effect of stroke) (two-way ANOVA with post hoc Bonferroni tests). ${ }^{\#} p<0.05$, Veh versus Dz (effect of treatment) (two-way ANOVA with post hoc Bonferroni tests). $\boldsymbol{H}-\boldsymbol{J}$, mRNA levels in the 1 month poststroke brain of Apoe K0 mice, $L x r(\boldsymbol{H}), \operatorname{Abca1}(\boldsymbol{I})$, and $A b c g 1(\boldsymbol{J}) ; n=10-13 / g r o u p$. ${ }^{*} p<0.05$ versus contralateral side (two-way ANOVA and post hoc Newman-Keuls test). ${ }^{* *} p<0.01$ versus contralateral side (two-way ANOVA and post hoc Newman-Keuls test). ${ }^{* * *} p<0.001$ versus contralateral side (two-way ANOVA and post hoc Newman-Keuls test). ${ }^{*} p<0.05$ versus Veh ipsilateral (two-way ANOVA and post hoc Newman-Keuls test). ${ }^{\# \#} p<$ 0.01 versus Veh ipsilateral (two-way ANOVA and post hoc Newman-Keuls test).

mRNA in the contralateral hemisphere may cause subsequent benefits in stroke recovery.

There is no reported deficit in neurocognitive and retinal function in a human subject lacking functional $A P O E$ gene expression (Mak et al., 2014). In agreement with this clinical finding, ApoE deficiency in mice did not affect baseline behaviors in this study (preischemic rotarod C57 vs Apoe KO, $253 \pm$ $49.4 \mathrm{~s}, 222.8 \pm 48.1 \mathrm{~s}, n=19$, notsignificant). In addition, we have previously shown that the infarct size and hemispheric swelling were similar in WT versus Apoe KO mice (E. Kim et al., 2008). This study, however, revealed a critical role of ApoE in injury paradigm. Following stroke, Apoe KO mice treated with daidzein did not display functional gains, even though daidzein significantly increased $L x r$ and Abcal mRNA levels (Fig. 7). Thus, in the absence of the ApoE gene, Abcal and Lxr were inadequate to produce functional benefits, indicating a necessary role for ApoE in fostering daidzein-promoted functional recovery.
Because of its reduced capacity for lipidation and efflux of cholesterol and phospholipids, $A P O E \varepsilon 4$ has been linked to a high risk of developing Alzheimer's disease (AD) (Michikawa et al., 2000; Hanson et al., 2013). Because ApoE expression level is a risk factor for $\mathrm{AD}$ regardless of $\mathrm{APOE} \varepsilon 4$ allele status (Maloney et al., 2010), enhancing ApoE and other cholesterol transporter expression by activating LXRs and RXRs has been suggested as a way to improve AD pathology (MandrekarColucci and Landreth, 2011; Cramer et al., 2012; BoehmCagan and Michaelson, 2014). The current study provides the mechanistic evidence of ApoE for daidzein-induced functional benefits and synaptophysin upregulation. Of particular interest, in light of our functional daidzein results is that $A P O E \varepsilon 4$ presence predicted age-related gait speed decline in men (Verghese et al., 2013). Likewise, the presence of the $A P O E \varepsilon 4$ allele is associated with reduced short- and long-term recovery from stroke (Cramer and Procaccio, 2012). Our working model is daidzein-induced upregulation of $L x r$ and 


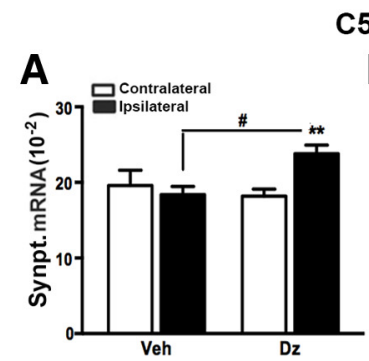

E

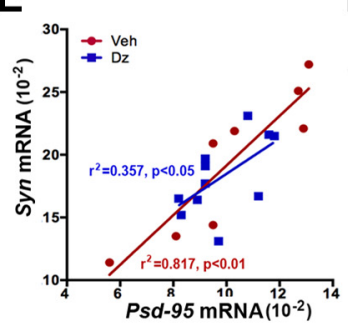

1

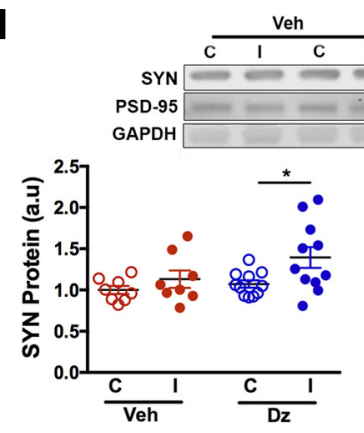

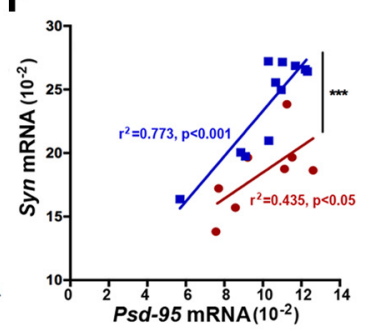

B

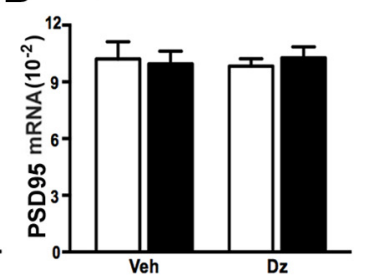

$\mathbf{F}$
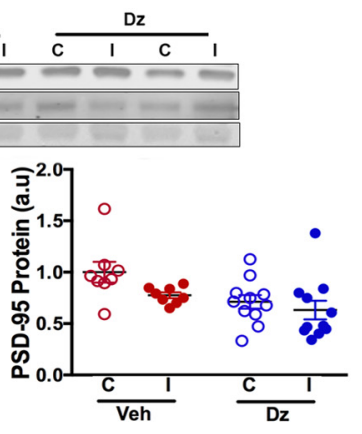

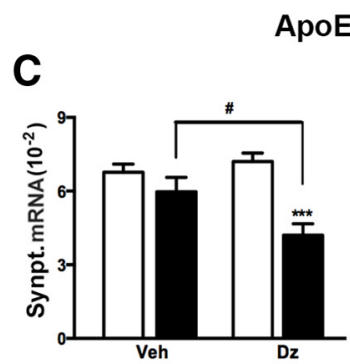

G
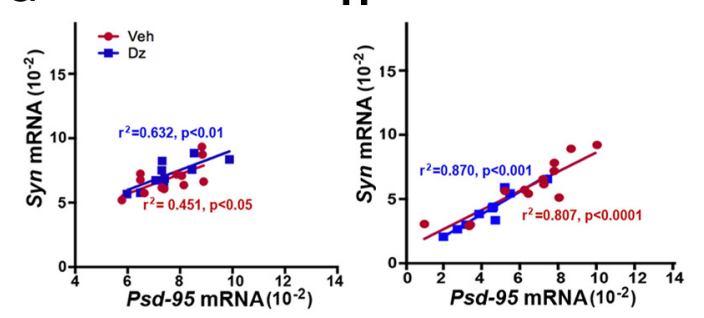

J
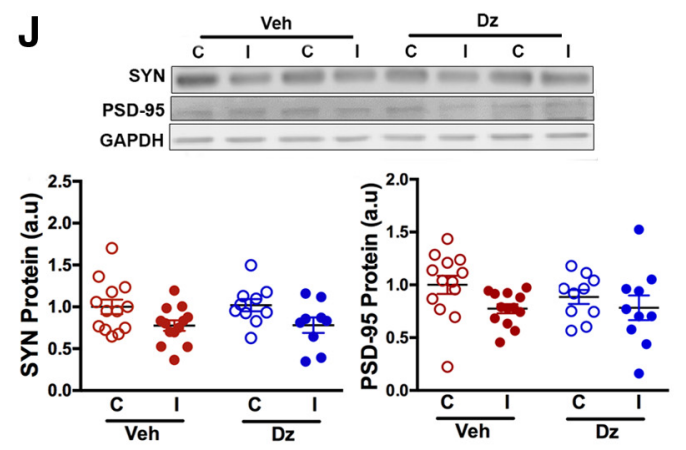

Figure 8. ApoE is necessary for daidzein-induced synaptophysin expression in chronic stroke. Presynaptic and postsynaptic marker expression at 1 month after stroke in $C 57$ (left, $A$, $\boldsymbol{B}, \boldsymbol{E}, \boldsymbol{F}, \boldsymbol{I}$ ) and Apoe KO (right, $\boldsymbol{C}, \boldsymbol{D}, \boldsymbol{G}, \boldsymbol{H}, \boldsymbol{J})$ mice. $\boldsymbol{A}-\boldsymbol{D}$, Synaptophysin and Psd-95 mRNA levels in $(57(\boldsymbol{A}, \boldsymbol{B})$ and $A$ poe K0 $(\boldsymbol{C}, \boldsymbol{D})$ mice. $\boldsymbol{y}$-axis represents mRNA levels normalized by actin. ${ }^{* *} p<0.01$ versus contralateral side (two-way ANOVA and post hoc Newman-Keuls test). ${ }^{* *} p<0.001$ versus contralateral side (two-way ANOVA and post hoc Newman-Keuls test). ${ }^{\#} p<0.05$ versus Veh ipsilateral side (two-way ANOVA and post hoc Newman-Keuls test). $\boldsymbol{E}-\boldsymbol{H}$, Correlation between Synaptophysin (Syn) and Psd-95 gene expression in the (57 contralateral $(\boldsymbol{E})$ and ipsilateral $(\boldsymbol{F})$ hemisphere and Apoe K0 contralateral $(\boldsymbol{G})$ and ipsilateral $(\boldsymbol{H})$ hemisphere. ${ }^{* * *} p<0.001$, slope difference between Veh- and Dz-treated groups. $\boldsymbol{I}, \boldsymbol{J}$, Synaptophysin (SYN) and PSD-95 protein expression in C57 (I) and Apoe K0 $(\boldsymbol{J})$ mice. $n=8-12$ /group for both genotypes. ${ }^{*} p<0.05$ versus contralateral side (two-way ANOVA and post hoc Newman-Keuls test). C, Contralateral; I, ipsilateral.

transporter genes provide a larger substrate base for conventional cholesterol effusion.

The required ApoE for daidzein-induced synaptophysin upregulation suggests mechanisms for cholesterol uptake into neurons. Low-density lipoprotein-related receptor protein-1 (LRP1) is an ApoE receptor that involves receptor-mediated endocytosis for cholesterol transport. Notably, we found that Lrp 1 mRNA level in the brain was high in the ipsilateral hemisphere at 1 month after stroke $(\sim 10$-fold higher than lowdensity lipoprotein receptor gene $L d l r$; Table 2). Correlation analyses showed that stroke-induced $L r p 1$ expression is significantly correlated with Apoe $\left(r^{2}=0.399, p<0.05, n=8\right)$ and synaptophysin mRNA $\left(r^{2}=0.432, p<0.05, n=8\right)$ in a daidzein-treated group, but not in a vehicle-treated group. Although there was no significant correlation between Apoe and synaptophysin mRNA levels, the correlation slope in daidzein-treated group was significantly elevated $(p<0.01$, $n=8$ ). Therefore, it is unlikely that ApoE directly regulates synaptophysin transcription in the presence of daidzein, but rather through LRP1 for ApoE uptake for synaptophysin expression. Thus, daidzein is likely promoting the directional movement of cholesterol through LRP1 in the injured brain for neurite outgrowth for plastic changes.
Through the gain and loss of ApoE coupled with molecular and functional studies, the current study demonstrated that daidzein-induced ApoE is critical for functional recovery in chronic stroke. The caveat of the study is a need to provide relevance of the preclinical findings in mice to human patients. Nevertheless, the similarities in the anatomical organization of lumbar pattern generators and locomotor control mechanisms between humans and rodents (Gerasimenko et al., 2008) suggest shared mechanisms in locomotor/kinematic recovery following stroke. As walking speed is one of the best determinants of community ambulation and of high priority to patients in the immediate aftermath of a paralytic stroke, our findings of better locomotion, faster gait speed, larger stride length and swing speed at the system levels, together with elevated ApoE and synaptophysin expression at the cellular level, provide a biological rationale for strategies aimed at augmenting ApoE for stroke recovery. With its known safety in humans, early and chronic use of clinically approved daidzein to aim at ApoE upregulation without having adverse effect on infarct size may serve as a novel, translatable strategy to promote recovery in stroke patients. Moreover, the findings should serve to catalyze additional studies on the association 
of prevalent ApoE isoforms with outcomes following stroke in humans.

\section{References}

Boehm-Cagan A, Michaelson DM (2014) Reversal of apoE4-driven brain pathology and behavioral deficits by bexarotene. J Neurosci 34:72937301. CrossRef Medline

Carmichael ST (2005) Rodent models of focal stroke: size, mechanism, and purpose. NeuroRx 2:396-409. CrossRef Medline

Carmichael ST (2006) Cellular and molecular mechanisms of neural repair after stroke: making waves. Ann Neurol 59:735-742. CrossRef Medline

Chen J, Zacharek A, Cui X, Shehadah A, Jiang H, Roberts C, Lu M, Chopp M (2010) Treatment of stroke with a synthetic liver X receptor agonist, TO901317, promotes synaptic plasticity and axonal regeneration in mice. J Cereb Blood Flow Metab 30:102-109. CrossRef Medline

Chen S, Wang JM, Irwin RW, Yao J, Liu L, Brinton RD (2011) Allopregnanolone promotes regeneration and reduces beta-amyloid burden in a preclinical model of Alzheimer's disease. PLoS One 6:e24293. CrossRef Medline

Chisholm JW, Hong J, Mills SA, Lawn RM (2003) The LXR ligand T0901317 induces severe lipogenesis in the $\mathrm{db} / \mathrm{db}$ diabetic mouse. J Lipid Res 44: 2039-2048. CrossRef Medline

Clarkson AN, Huang BS, Macisaac SE, Mody I, Carmichael ST (2010) Reducing excessive GABA-mediated tonic inhibition promotes functional recovery after stroke. Nature 468:305-309. CrossRef Medline

Coldham NG, Sauer MJ (2000) Pharmacokinetics of [(14)C]Genistein in the rat: gender-related differences, potential mechanisms of biological action, and implications for human health. Toxicol Appl Pharmacol 164: 206-215. CrossRef Medline

Cramer PE, Cirrito JR, Wesson DW, Lee CY, Karlo JC, Zinn AE, Casali BT, Restivo JL, Goebel WD, James MJ, Brunden KR, Wilson DA, Landreth GE (2012) ApoE-directed therapeutics rapidly clear beta-amyloid and reverse deficits in AD mouse models. Science 335:1503-1506. CrossRef Medline

Cramer SC, Procaccio V (2012) Correlation between genetic polymorphisms and stroke recovery: analysis of the GAIN Americas and GAIN International Studies. Eur J Neurol 19:718-724. CrossRef Medline

Darling WG, Pizzimenti MA, Hynes SM, Rotella DL, Headley G, Ge J, Stilwell-Morecraft KS, McNeal DW, Solon-Cline KM, Morecraft RJ (2011) Volumetric effects of motor cortex injury on recovery of ipsilesional dexterous movements. Exp Neurol 231:56-71. CrossRef Medline

Gao J, Xu Y, Yang Y, Yang Y, Zheng Z, Jiang W, Hong B, Yan X, Si S (2008) Identification of upregulators of human ATP-binding cassette transporter Al via high-throughput screening of a synthetic and natural compound library. J Biomol Screen 13:648-656. CrossRef Medline

Gerasimenko Y, Roy RR, Edgerton VR (2008) Epidural stimulation: comparison of the spinal circuits that generate and control locomotion in rats, cats and humans. Exp Neurol 209:417-425. CrossRef Medline

Gonzalez CL, Gharbawie OA, Williams PT, Kleim JA, Kolb B, Whishaw IQ (2004) Evidence for bilateral control of skilled movements: ipsilateral skilled forelimb reaching deficits and functional recovery in rats follow motor cortex and lateral frontal cortex lesions. Eur J Neurosci 20:34423452. CrossRef Medline

Grefhorst A, Elzinga BM, Voshol PJ, Plösch T, Kok T, Bloks VW, van der Sluijs FH, Havekes LM, Romijn JA, Verkade HJ, Kuipers F (2002) Stimulation of lipogenesis by pharmacological activation of the liver $\mathrm{X}$ receptor leads to production of large, triglyceride-rich very low density lipoprotein particles. J Biol Chem 277:34182-34190. CrossRef Medline

Hanson AJ, Bayer-Carter JL, Green PS, Montine TJ, Wilkinson CW, Baker LD, Watson GS, Bonner LM, Callaghan M, Leverenz JB, Tsai E, Postupna N, Zhang J, Lampe J, Craft S (2013) Effect of apolipoprotein E genotype and diet on apolipoprotein E lipidation and amyloid peptides: randomized clinical trial. JAMA Neurol 70:972-980. CrossRef Medline

Haskew-Layton RE, Payappilly JB, Smirnova NA, Ma TC, Chan KK, Murphy TH, Guo H, Langley B, Sultana R, Butterfield DA, Santagata S, Alldred MJ, Gazaryan IG, Bell GW, Ginsberg SD, Ratan RR (2010) Controlled enzymatic production of astrocytic hydrogen peroxide protects neurons from oxidative stress via an Nrf2-independent pathway. Proc Natl Acad Sci U S A 107:17385-17390. CrossRef Medline

Hurtado O, Ballesteros I, Cuartero MI, Moraga A, Pradillo JM, RamírezFranco J, Bartolomé-Martin D, Pascual D, Torres M, Sánchez-Prieto J, Salom JB, Lizasoain I, Moro MA (2012) Daidzein has neuroprotective effects through ligand-binding-independent PPARgamma activation. Neurochem Int 61:119-127. CrossRef Medline

Jung JH, Kim HS (2013) The inhibitory effect of black soybean on hepatic cholesterol accumulation in high cholesterol and high fat diet-induced non-alcoholic fatty liver disease. Food Chem Toxicol 60:404-412. CrossRef Medline

Karten B, Campenot RB, Vance DE, Vance JE (2006) Expression of ABCG1, but not $\mathrm{ABCA} 1$, correlates with cholesterol release by cerebellar astroglia. J Biol Chem 281:4049-4057. CrossRef Medline

Kennedy MA, Venkateswaran A, Tarr PT, Xenarios I, Kudoh J, Shimizu N, Edwards PA (2001) Characterization of the human ABCG1 gene: liver X receptor activates an internal promoter that produces a novel transcript encoding an alternative form of the protein. J Biol Chem 276:3943839447. CrossRef Medline

Kim E, Tolhurst AT, Qin LY, Chen XY, Febbraio M, Cho S (2008) CD36/ fatty acid translocase, an inflammatory mediator, is involved in hyperlipidemia-induced exacerbation in ischemic brain injury. J Neurosci 28:4661-4670. CrossRef Medline

Kim E, Febbraio M, Bao Y, Tolhurst AT, Epstein JM, Cho S (2012) CD36 in the periphery and brain synergizes in stroke injury in hyperlipidemia. Ann Neurol 71:753-764. CrossRef Medline

Kim E, Tolhurst AT, Cho S (2014) Deregulation of inflammatory response in the diabetic condition is associated with increased ischemic brain injury. J Neuroinflamm 11:83. CrossRef Medline

Kim WS, Weickert CS, Garner B (2008) Role of ATP-binding cassette transporters in brain lipid transport and neurological disease. J Neurochem 104:1145-1166. CrossRef Medline

King RA, Bursill DB (1998) Plasma and urinary kinetics of the isoflavones daidzein and genistein after a single soy meal in humans. Am J Clin Nutr 67:867-872. Medline

Kratzer A, Buchebner M, Pfeifer T, Becker TM, Uray G, Miyazaki M, Miyazaki-Anzai S, Ebner B, Chandak PG, Kadam RS, Calayir E, Rathke N, Ahammer H, Radovic B, Trauner M, Hoefler G, Kompella UB, Fauler G, Levi M, Levak-Frank S, et al. (2009) Synthetic LXR agonist attenuates plaque formation in $\mathrm{apoE}^{-1-}$ mice without inducing liver steatosis and hypertriglyceridemia. J Lipid Res 50:312-326. Medline

Langmann T, Porsch-Ozcürümez M, Heimerl S, Probst M, Moehle C, Taher M, Borsukova H, Kielar D, Kaminski WE, Dittrich-Wengenroth E, Schmitz G (2002) Identification of sterol-independent regulatory elements in the human ATP-binding cassette transporter A1 promoter: role of Sp1/3, E-box binding factors, and an oncostatin M-responsive element. J Biol Chem 277:14443-14450. CrossRef Medline

Lin TN, He YY, Wu G, Khan M, Hsu CY (1993) Effect of brain edema on infarct volume in a focal cerebral ischemia model in rats. Stroke 24: 117-121. CrossRef Medline

Ma TC, Campana A, Lange PS, Lee HH, Banerjee K, Bryson JB, Mahishi L, Alam S, Giger RJ, Barnes S, Morris SM Jr, Willis DE, Twiss JL, Filbin MT, Ratan RR (2010) A large-scale chemical screen for regulators of the arginase 1 promoter identifies the soy isoflavone daidzeinas a clinically approved small molecule that can promote neuronal protection or regeneration via a cAMP-independent pathway. J Neurosci 30:739-748. CrossRef Medline

Mahley RW, Rall SC Jr (2000) Apolipoprotein E: far more than a lipid transport protein. Annu Rev Genom Hum Genet 1:507-537. CrossRef Medline

Mak AC, Pullinger CR, Tang LF, Wong JS, Deo RC, Schwarz JM, Gugliucci A, Movsesyan I, Ishida BY, Chu C, Poon A, Kim P, Stock EO, Schaefer EJ, Asztalos BF, Castellano JM, Wyss-Coray T, Duncan JL, Miller BL, Kane JP, et al. (2014) Effects of the absence of apolipoprotein E on lipoproteins, neurocognitive function, and retinal function. JAMA Neurol 71: 1228-1236. CrossRef Medline

Maloney B, Ge YW, Alley GM, Lahiri DK (2007) Important differences between human and mouse APOE gene promoters: limitation of mouse APOE model in studying Alzheimer's disease. J Neurochem 103: 1237-1257. CrossRef Medline

Maloney B, Ge YW, Petersen RC, Hardy J, Rogers JT, Perez-Tur J, Lahiri DK (2010) Functional characterization of three single-nucleotide polymorphisms present in the human APOE promoter sequence: differential effects in neuronal cells and on DNA-protein interactions. Am J Med Genet B Neuropsychiatr Genet 153B:185-201. CrossRef Medline

Mandrekar-Colucci S, Landreth GE (2011) Nuclear receptors as therapeutic targets for Alzheimer's disease. Expert Opin Ther Targets 15:1085-1097. CrossRef Medline 
Meisel C, Prass K, Braun J, Victorov I, Wolf T, Megow D, Halle E, Volk HD, Dirnagl U, Meisel A (2004) Preventive antibacterial treatment improves the general medical and neurological outcome in a mouse model of stroke. Stroke 35:2-6. CrossRef Medline

Mezei O, Banz WJ, Steger RW, Peluso MR, Winters TA, Shay N (2003) Soy isoflavones exert antidiabetic and hypolipidemic effects through the PPAR pathways in obese Zucker rats and murine RAW 264.7 cells. J Nutr 133:1238-1243. Medline

Michikawa M, Fan QW, Isobe I, Yanagisawa K (2000) Apolipoprotein E exhibits isoform-specific promotion of lipid efflux from astrocytes and neurons in culture. J Neurochem 74:1008-1016. CrossRef Medline

Nudo RJ (2007) Postinfarct cortical plasticity and behavioral recovery. Stroke 38:840-845. CrossRef Medline

Orgaard A, Jensen L (2008) The effects of soy isoflavones on obesity. Exp Biol Med 233:1066-1080. CrossRef Medline

Pandian S, Arya KN (2013) Motor impairment of the ipsilesional body side in poststroke subjects. J Bodyw Mov Ther 17:495-503. CrossRef Medline

Pfrieger FW (2003) Outsourcing in the brain: do neurons depend on cholesterol delivery by astrocytes? Bioessays 25:72-78. CrossRef Medline

Qin L, Jing D, Parauda S, Carmel J, Ratan RR, Lee FS, Cho S (2014) An adaptive role for BDNF Val66Met polymorphism in motor recovery in chronic stroke. J Neurosci 34:2493-2502. CrossRef Medline

Rasbach KA, Schnellmann RG (2008) Isoflavones promote mitochondrial biogenesis. J Pharmacol Exp Ther 325:536-543. CrossRef Medline

Ricketts ML, Moore DD, Banz WJ, Mezei O, Shay NF (2005) Molecular mechanisms of action of the soy isoflavones includes activation of promiscuous nuclear receptors: a review. J Nutr Biochem 16:321-330. CrossRef Medline

Rivera P, Pérez-Martín M, Pavón FJ, Serrano A, Crespillo A, Cifuentes M, López-Ávalos MD, Grondona JM, Vida M, Fernández-Llebrez P, de Fonseca FR, Suárez J (2013) Pharmacological administration of the isoflavone daidzein enhances cell proliferation and reduces high fat dietinduced apoptosis and gliosis in the rat hippocampus. PLoS One 8:e64750. CrossRef Medline

Schaefer SY, Haaland KY, Sainburg RL (2009) Hemispheric specialization and functional impact of ipsilesional deficits in movement coordination and accuracy. Neuropsychologia 47:2953-2966. CrossRef Medline

Shih SJ, Allan C, Grehan S, Tse E, Moran C, Taylor JM (2000) Duplicated downstream enhancers control expression of the human apolipoprotein E gene in macrophages and adipose tissue. J Biol Chem 275:31567-31572. CrossRef Medline
Soumyakrishnan S, Divya T, Kalayarasan S, Sriram N, Sudhandiran G (2014) Daidzein exhibits anti-fibrotic effect by reducing the expressions of Proteinase activated receptor 2 and TGFbetal/smad mediated inflammation and apoptosis in Bleomycin-induced experimental pulmonary fibrosis. Biochimie 103:23-36. CrossRef Medline

Stout JM, Knapp AN, Banz WJ, Wallace DG, Cheatwood JL (2013) Subcutaneous daidzein administration enhances recovery of skilled ladder rung walking performance following stroke in rats. Behav Brain Res 256: 428-431. CrossRef Medline

Sung JH, Choi SJ, Lee SW, Park KH, Moon TW (2004) Isoflavones found in Korean soybean paste as 3-hydroxy-3-methylglutaryl Coenzyme A reductase inhibitors. Biosci Biotech Bioch 68:1051-1058. CrossRef Medline

Swanson LW (1995) Mapping the human brain: past, present, and future. Trends Neurosci 18:471-474. CrossRef Medline

Terasaka N, Hiroshima A, Koieyama T, Ubukata N, Morikawa Y, Nakai D, Inaba $\mathrm{T}$ (2003) T-0901317, a synthetic liver $\mathrm{X}$ receptor ligand, inhibits development of atherosclerosis in LDL receptor-deficient mice. FEBS Lett 536:6-11. CrossRef Medline

van Meer MP, van der Marel K, Wang K, Otte WM, El Bouazati S, Roeling TA, Viergever MA, Berkelbach van der Sprenkel JW, Dijkhuizen RM (2010) Recovery of sensorimotor function after experimental stroke correlates with restoration of resting-state interhemispheric functional connectivity. J Neurosci 30:3964-3972. CrossRef Medline

Verghese J, Holtzer R, Wang C, Katz MJ, Barzilai N, Lipton RB (2013) Role of APOE genotype in gait decline and disability in aging. J Gerontol A Biol Sci Med Sci 68:1395-1401. CrossRef Medline

Wang P, Jeng CJ, Chien CL, Wang SM (2008) Signaling mechanisms of daidzein-induced axonal outgrowth in hippocampal neurons. Biochem Biophys Res Commun 366:393-400. CrossRef Medline

Wenzel U, Fuchs D, Daniel H (2008) Protective effects of soy-isoflavones in cardiovascular disease: identification of molecular targets. Hamostaseologie 28:85-88. Medline

Whitney KD, Watson MA, Collins JL, Benson WG, Stone TM, Numerick MJ, Tippin TK, Wilson JG, Winegar DA, Kliewer SA (2002) Regulation of cholesterol homeostasis by the liver $\mathrm{X}$ receptors in the central nervous system. Mol Endocrinol 16:1378-1385. CrossRef Medline

Zeiler SR, Gibson EM, Hoesch RE, Li MY, Worley PF, O’Brien RJ, Krakauer JW (2013) Medial premotor cortex shows a reduction in inhibitory markers and mediates recovery in a mouse model of focal stroke. Stroke 44:483-489. CrossRef Medline 